\title{
AIAA 2000-4012
}

\section{Hypersonic Boundary-Layer Trip Development for Hyper-X}

Scott A. Berry, Aaron H. Auslender, Authur D. Dilley, NASA Langley Research Center, Hampton, VA 23681

and John F. Calleja

GASL, Inc.

Ronkonkoma, NY 11779

\section{8th AIAA Applied Aerodynamics Conference 14-17 August 2000 / Denver, CO}





\title{
Hypersonic Boundary-Layer Trip Development for Hyper-X
}

\author{
Scott A. Berry". Aaron H. Auslender ${ }^{*}$, and Arthur D. Dilley ${ }^{*}$ \\ NASA Langley Research Center, Hampton, VA \\ and \\ John F. Calleja \\ GASL, Inc., Ronkonkoma, NY
}

\begin{abstract}
Boundary laver trip devices for the Hyper-X forebody have been experimentally examined in several wind tunnels. Five different trip configurations were compared in three hypersonic facilities, the LaRC 20-Inch Mach 6 Air Tunnel, the LaRC 3I-Inch Mach IO Air Tunnel, and in the HYPULSE Reflected Shock Tunnel at GASL. Heat transfer distributions. utilizing the phosphor thermography and thin-film techniques, shock system details, and surface streamline patterns were measured on a 0.333 -scale model of the Hyper-X forebody. Parametric variations include angles-of-attack of 0-deg. 2-deg, and 4-deg: Revnolds numbers based on model length of 1.2 to 15.4 million; and inlet cowl door simulated in both open and closed positions. Comparisons of transition due to discrete roughness elements have led to the selection of a trip configuration for the Hyper-X Mach 7 flight vehicle.

\section{Nomenclature}

$\mathrm{Re}_{\mathrm{L}} \quad$ Reynolds number based on body length

$\mathrm{Re}_{\mathrm{H}} \quad$ momentum thickness Reynolds number

$\begin{array}{ll}\text { aw } & \text { adiabatic wall } \\ \text { e } & \text { conditions at edge of the boundary layer } \\ \text { w } & \text { model surface } \\ \text { inc } & \text { incipient } \\ \text { cr } & \text { critical } \\ \text { eff } & \text { effective }\end{array}$
\end{abstract}

M Mach number

Re unit Reynolds number ( $1 / \mathrm{ft})$

$R_{n} \quad$ nose radius (in)

$\alpha \quad$ model angle of attack (deg)

$\delta \quad$ boundary layer thickness (in)

p pressure (psi)

T temperature (R)

$\mathrm{x}$

y

Z

$\mathrm{L}$

$\mathrm{h}$

$\mathrm{h}_{\text {ref }}$

q

H

$\mathrm{k}$ Subscripts

$\infty \quad$ freestream static conditions

tl reservoir conditions

t2 stagnation conditions behind normal shock

\footnotetext{
* Aerospace Technologist. Aerothermodynamics Branch.

Assistant Branch Head. Hypersonic Airbreathing Propulsion Branch.

‡ Senior Researcher. FDC/NYMA. Inc

senior Research Scientist. Member AIAA.

Copyright 02000 by the American Institute of Aeronautics and

Astronautics, Inc. No copyright is asserted in the Inited States under

Title 17. U.S. Code. The U.S. Government has a royalty-free license to exercise all rights under the copyright claimed herein for government purposes. All other rights are reserved by the copyright owner.
}

\section{Introduction}

NASA's $X-43$ (Hyper-X) program will culminate with flight tests of an operational airframe-integrated scramjet propulsion system at hypersonic conditions. Currently, two flights at Mach 7 and one at Mach 10 are planned. Details about the flight and wind tunnel test program can be found in Rausch, et al. (1997a, 1997b) and McClinton, et al. (1998). A simulated launch sequence is shown in Fig. 1, along with the nominal Mach-7 flight trajectory. This program will provide the first opportunity to obtain flight data on an autonomous hypersonic air-breathing propulsion system that is fully integrated with the vehicle airframe, and will validate/calibrate the experimental, numerical, and analytical methods that were used for design and flight performance prediction. In an effort to reduce uncertainties associated with this cuttingedge technology maturation program prior to the first flight, a systematic and combined experimental and numerical approach has been utilized. This includes (but is not limited to) development of aerodynamic performance and aeroheating databases, verification of performance and operability of the propulsionairframe integration, and establishment of a method for boundary layer control. For instance, in order to provide the most robust scramjet propulsion system. 
the boundary layer approaching the scramjet inlet should be turbulent. Ingestion of a turbulent boundary layer increases inlet operability and therefore enhances overall engine performance. Based on the current knowledge of boundary layer transition for slender, planar configurations at hypersonic flight conditions, an estimation of the location of natural transition on the Hyper- $X$ forebody indicates that boundary layer trip devices are necessary to ensure a turbulent boundary layer at the inlet for both Mach 7 and 10 flights. To develop boundary layer trips for the Hyper-X vehicle, a wind tunnel test program was initiated at the NASA langley Research Center (LaRC).

Prior to the establishment of the Hyper-X program, preliminary experimental studies had been conducted to develop boundary layer trip devices for the Hyflite and HySTP (see Holland, et al., 1995) programs, which were also planned as sub-scale scramjet engine flight tests. While most of these results are still unpublished, a promising trip configuration was identified that effectively forced transition despite being smaller than the predicted boundary layer thickness. These early experiments did not attempt to optimize this trip configuration to further improve effectiveness or decrease trip drag. Thus, a trip optimization study was initiated for the Hyper-X program. whereby the original trip configuration became the benchmark with which to assess newer, potentially improved variations.

The trip screening testing sequence that has been completed to date is listed in Table 1. Testing has been conducted in the LaRC 20-Inch Mach 6 and 31Inch Mach 10 tunnels, as well as the NASA HYPIJSE facility at the General Applied Sciences Laboratory (GASL). The purpose of these tests was to compare various trip configurations for selection of a trip for the Hyper-X flight vehicle and to examine the effect of the discrete roughness elements on the aeroheating characteristics of the Hyper- $X$ forebody. Based on preflight trajectory information. the flight forchody length Reynolds number $\left(\mathrm{Re}_{\mathrm{L}}\right)$, for a forebody length of $6-\mathrm{ft}$. is approximately 5.5 million at a freestream Mach number of 7 . These conditions can be simulated in all three tunnels based on a model length of 28 -in $(2.3-\mathrm{ft})$, which provides for a $\mathrm{Re}_{\mathrm{l}}$, range on the order of 1.2 to 18.4 million. Test techniques that were utilized include thermographic phosphors (provides images of the global surface heating), thin-film (provides a distributed array of discrete heat transfer measurements), schlieren (provides detailed shock shapes), and oil-llow (provides surface streamline information). Parametrics included in these tests, with the inlet cowl door simulated in both the open and closed positions, were the effect of angle of attack ( $\alpha$ of 0 -deg, 2-deg, and 4-deg), unit Reynolds number (Re between 0.5 and 6.7 million per foot), and discrete roughness elements. The discrete roughness parametrics, which consisted of 5 configurations of various heights, were selected to provide guidelines for development of an efficient trip design for the Hyper- $X$ flight vehicle. By virtue of the test being conducted in the different facilities, the parametrics also include the effect of Mach number $\left(M_{x}\right.$ of $6,7.3$, and 10$)$ and total enthalpy $\left(H_{11}\right.$ between 200 and $1000 \mathrm{BTU} / \mathrm{lbm}$ ). The experimental data from both the LaRC. 20-Inch Mach 6 Air and 31 Inch Mach 10 Air tunnels are presented in Berry, et al. (2000a and 2000b), while the HYPULSE data are reported by Calleja (2000). This report presents an overview of the results from these three tunnels and details the methodology used for design of the trip for the Hyper-X Mach 7 flight vehicle.

\section{Trip Design}

As part of a fully integrated scramjet propulsion system, the Hyper-X vehicle windward forebody is designed to compress and process the flow going into the inlet. The windward forebody, see Fig. 2, is approximately 6-ft long and is characterized by a thin leading edge $\left(R_{n}=0.03-i n\right)$ and 3 flat ramps that provide a series of discrete, non-isentropic flowcompressions for the engine. While flying at the nominal angle of attack of 2 -deg, the first forebody ramp provides an initial 4.5-deg of compression. followed by the second ramp with an additional 5.5deg, and finally the third ramp with the final 3-deg of additional compression. Outboard of the flat ramps are the chines, which are designed to minimize threedimensional effects and flow spillage. Ideally, the forebody would also provide a turbulent boundary layer for the inlet. A full-scale scramjet-powered vehicle, such as NASP or a similar derivative. would likely have sufficient forebody length to provide a naturally turbulent boundary layer. Therefore, as a sub-scale vehicle, Hyper-X requires forced boundarylayer transition in order to properly scale the engine flight test results to a future full-scale vehicle. While the primary emphasis for the trips is to provide a turbulent boundary layer for the inlet, a secondary concern is whether a laminar separation at the end of the first ramp will promote lateral spillage of the forebody boundary layer away from the inlet, potentially reducing the mass capture and affecting performance. An analysis of the Hyper-X forebody 
using the hypersonic boundary layer transition criteria developed during the National Aerospace

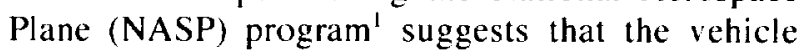
forebody will remain laminar during the flight. The results from this analysis are detailed in a Hyper-X Technical Note written by Dilley (1996). A boundary layer code was used to compute laminar values of $\mathrm{Re}_{\mathrm{H}} / \mathrm{M}_{\mathrm{e}}$ for a sharp nose wedge with 4.5-deg of turning. The NASP sharp planar transition criterion of $\mathrm{Re}_{\mathrm{t}} / \mathrm{M}_{\mathrm{e}}=305$ was used to estimate the onset of transition. For an initial assessment, this sharp planar criterion was deemed acceptable, as nose bluntness has a stabilizing influence that would further delay transition onset (Stetson, 1984). Based on this initial estimate, transition will not occur on the first ramp prior to the compression corner. In fact, over $200 \%$ more running length is required for transition to occur on the first ramp based on the accepted criterion, which is beyond the inlet. Thus, without some sort of flow tripping device, the potential exists for a laminar separation at the first ramp break to generate some degree of lateral spillage. As for the question of transition prior to the inlet, the discrete compression corners will tend to promote transition, but to what extent is unclear. Very little ground based experimental data is available to provide guidance on forced transition through the use of discrete compression corners, and certainly less flight experience. To be conservative, the decision was made to force transition through the use of a passive (non-retractable) trip array on the first ramp to ensure, at the very least, turbulent flow into the inlet, and also provide some flow spillage relief at the first ramp break.

The design of the Hyper- $X$ trips was primarily predicated on empirical "rules-of-thumb" that were used to reduce the size of the experimental matrix. These rules-of-thumb were identified early in the formulation of this test program from an ad hoc hypersonic boundary layer transition panel (see acknowledgements). First, the general empirical design criteria dictated that the "tripping" mechanism most effective in forcing hypersonic transition required the formation of streamwise vorticity on a scale within the boundary layer. Thus, the strategy was to create a series of counter rotating vortex pairs emanating from a spanwise mixer array, comprised

\footnotetext{
${ }^{1}$ While much of the NASP documentation is currently still classified, the boundary layer transition criteria developed during NASP are considered unclassified. Lau and Vaporean (1992) discuss the NASP transition database.
}

of numerous trip elements that were moderately smaller than the boundary layer height. Initial analysis of the candidate trip configurations determined that, due to their relatively small size, the associated drag penalty to the vehicle would be minimal (Dilley, 1996). Furthermore, the placement of the array. downstream of the vehicle leading edge. was selected to be in the vicinity of a local Mach number $\left(\mathbf{M}_{\mathrm{e}}\right)$ at the boundary layer edge of less than four (see Reshotko, 1976). While $\mathrm{M}_{\mathrm{c}}$ rises rapidly near the leading edge, the first forebody ramp provides a wide domain of acceptable edge conditions. For the Mach 7 vehicle, the mid-point (roughly) on the first ramp was selected as a compromise between locations close to the leading edge where $M_{e}$ would be less and locations away from the leading edge where the sub-structure would be thicker and could easily accommodate the trip insert.

It has been widely recognized that ground-based testing of boundary layer transition is influenced by tunnel noise (for instance, see Reed, et al. 1998). Determination of a natural hypersonic boundary-layer transition criteria based on wind tunnel data is made more difficult due to the differences in the freestream turbulence levels between ground-based facilities and flight. Also, the process of extrapolating forcedtransition ground-test data to flight environments is even less well understood. At present, as detailed by Malik (1989), a comprehensive theoretical analysis of natural hypersonic boundary layer transition mechanisms is beyond current computational capabilities, let alone the more difficult task of characterizing forced, axial-vortex transition processes. Many researchers have reported that natural transition at hypersonic conditions appears to be dominated by the higher frequency disturbances (second-mode instabilities). Kendall (1975) and Owen et al. (1975) have investigated facility induced noise effects on natural transition mechanisms (by varying tunnel fluctuation levels and employing different test facilities, respectively) and concluded that this factor is not significant for the hypersonic regime. Stetson (1990) has argued that conventional hypersonic wind tunnels can be considered effectively quiet, as most facilities generate acoustic disturbances of a much lower frequency than required to excite the dominate hypersonic instabilities. While there maybe merit to this argument. the fact remains that there is, as noted by Schneider $(2000)$. a wide disparity between natural transition Reynolds numbers from ground-based facilities and flight. However, Schneider (2000) also notes that trips that 
are large enough to cause transition onset at the roughness element ("effective" trips) are not significantly influenced by tunnel noise. Therefore, to minimize ground-based noise effects, the decision was made to test the trip configurations in several different facilities and to select the trip height that forces transition as close to the trip as possible.

Over the course of this experimental program, a total of five trip configurations, shown in Fig. 3. were tested and compared. Initially, only four trips were considered and were designated as Trip 1 for the original baseline and Trips $2 \mathrm{a}, 2 \mathrm{~b}$, and 3 for the new variations. However, late in the testing sequence a slight modification to the Trip $2 b$ configuration was proposed and was designated as Trip $2 \mathrm{c}$ (shown in Fig. 3d). Trip 1, the "diamond" configuration, was based on prior experience during LaRC studies involving the Shuttle Orbiter (Berry, et al. 1998), X38 (Berry, et al. 1997a and Horvath, et al. 2000), and X-3.3 (Berry, et al. 1999b), as well as for the NASP. Hyflite, and HySTP programs (unpublished data; a pre-test report for the HySTP test is provided by Holland, et al.. 1995), and can be best described as a double wedge placed back-to-back forming a square with one of the corners pointing forward. In these previous studies, this basic geometry has been shown to be a highly efficient vortex generator and trip. Similar trip elements have been tested in the past. Hama (1957, 1964) used a row of single (triangular) wedges with one tip facing forward and the other tips louching the adjacent wedge and reported better forced transition results than using spherical trips. Demetriades (1991) also tested a single wedge, as well as other trip configurations, but used trip heights several times larger than the boundary layer thickness. Unlike Demetriades' results, the diamond configuration has been shown to force transition using heights smaller than the boundary layer thickness. Infortunately for the Hyper-X program. the diamond configuration had two potentially significant drawbacks that necessitated the current study. Vortices produced by the diamond configuration were rather strong and tended to persist well into the turbulent region (which could provide a non-uniform flowfield for the inlet and enhanced closed-door heating levels). Also, of concern was whether the blunt face of this trip configuration would contribute unnecessary drag and if the trip could be structurally designed for Mach 7 (and 10) flight conditions. The new configurations, all essentially swept ramps of different types, were selected as modifications to this original trip design with the intent of providing a vortex-generating trip as effective as Trip 1, but without the flow nonuniformity, trip drag and structural concerns.

Conceptually, the trip configuration selected for the Mach 7 flight vehicle consists of a lateral array of vortex generators (VG) on the first ramp of the Hyper-X forebody. The dimensions of the unit-VG were selected to be on the order of the scale of the predicted boundary layer thickness. Several unit-VG configurations were experimentally examined to obtain the most efficient trip design for a given fraction of the forebody boundary layer thickness. The trip screening process also assessed each unitVG design for thermal survivability, trip drag. and the effect of the trip configuration on the potential heating to the closed cowl door during the ascent trajectory. Once a final trip configuration was selected, the experimental data were used to determine the appropriate scaling, with respect to the boundary layer thickness, to ensure not only turbulent inflow into the inlet but also minimal forebody lateral spillage (due to potential flow separations of a laminar forebody) which would adversely affect the engine mass capture. Lastly, the trips were sized for the Mach 7 vehicle. using predictions of the boundary layer thickness in flight, for a dispersion range of angles of attack ( $\alpha=2-\mathrm{deg} \pm 1-\mathrm{deg}$ ) and to account for uncertainties associated with wall temperature effects. Details of the actual trip configuration and geometry selected for the Mach 7 flight vehicle will be discussed in a subsequent section.

\section{Experimental Methods}

\section{Test Facilities}

The Hyper-X forebody model has been tested in both the 20-Inch Mach 6 Air and the 31-Inch Mach 10 Air Tunnels of the LaRC Aerothermodynamic Facilities Complex (AFC), as well as the NASA HYPULSE facility located at GASL, Inc. in Ronkonkoma, NY. The AFC facilities are conventional blow-down tunnels that utilize dried, heated, and filtered air as the test gas. Detailed descriptions of these facilities and their associated instrumentation are found in Miller (1990) and Micol (1998). HYPILSE is a short-duration hypervelocity facility that was originally operated at NASA LaRC as an expansion tube (see Miller and Jones 1983).

Typical operating conditions for the IaRC 20Inch Mach 6 Air Tunnel are stagnation pressures ranging from 30 to 500 psia, stagnation temperatures from 410 to $500^{\circ} \mathrm{F}$, and free stream unit Reynolds numbers of 0.5 to $7.8 \times 10^{6} / \mathrm{ft}$. A two-dimensional. contoured nozzle is used to provide a nominal 
freestream Mach number of 6 . The test section is 20.5 by 20 inches. A bottom-mounted model injection system inserts models from a sheltered position to the tunnel centerline in less than 0.5 -sec. Run times of up to 15 minutes are possible with this facility, although for typical heat transfer and flow visualization tests, only a few seconds are required. Optical access to the model was viewed through a high-quality window on the top of the tunnel for phosphors and oil-flow, while high-quality windows on the side provided schlieren access.

Typical operating conditions for the LaRC 31 Inch Mach 10 Air Tunnel are stagnation pressures ranging from 350 to 1450 psia and a stagnation temperature on the order of $1350^{\circ} \mathrm{F}$, which yields freestream unit Reynolds numbers of $0.5 \times 10^{6} / \mathrm{ft}$ to $2.2 \times 10^{6} / \mathrm{ft}$. The tunnel has a closed $31-$ by 31 -in. test section with a contoured three-dimensional watercooled nozzle to provide a nominal Mach number of 10. A hydraulically operated side-mounted model injection mechanism injects the model into the flow in 0.6 seconds. The maximum run time for this facility is approximately 2 minutes; however, only 5 seconds of this time is typically required for transient heat transfer tests. Optical access to the model mechanism for both phosphors and oil-flow is viewed through a high-quality side window.

The NASA HYPILSE has been operated by GASL, Inc. since 1989, and was recommissioned in support of scramjet research during the NASP program. HYPULSE was initially run in the shockexpansion tunnel (SET) mode, producing hypervelocity flows that provided equivalent flight stagnation enthalpies ranging from Mach 12 to 2.5 . Recently. the facility has been re-configured to operate in a reflected-shock tunnel (RST) mode with a nozzle (2-in diameter throat and 26.5-in diameter exit plane) that expands the flow into a 7-ft diameter test section, as detailed by Modroukas, et al. (1998). When operating in the RST mode, equivalent flight stagnation enthalpies in the Mach 5 to 12 range can be produced. Operation of HYPULSE in both the SET and RST modes is documented in Tamagno, et al. (1990), Erdos, et al. (1994), and Bakos, et al. (1996a and b). Typical test times for HYPULSE operated in a RST mode is on the order of 4 milliseconds. which is roughly an order of magnitude greater than that achieved in a SET mode.

\section{Test Techniques}

A two-color, relative-intensity phosphor thermography system is currently being utilized for aeroheating tests in LaRC's AFC. Buck (1989, 1991) and Merski (1998) provide details about the phosphor thermography technique. Horvath (2000) and Berry. et al. (1997a, 1999a, 1999b) are recent examples of the application of phosphor thermography to wind tunnel testing. With this technique, ceramic wind tunnel models are fabricated and coated with phosphors that fluoresce in two regions of the visible spectrum when illuminated with ultraviolet light. The fluorescence intensity is dependent upon the amount of incident ultraviolet light and the local surface temperature of the phosphors. By acquiring fluorescence intensity images with a color video camera of an illuminated phosphor model exposed to flow in a wind tunnel, surface temperature mappings are calculated on the portions of the model that are in the field of view of the camera. A temperature calibration of the system conducted prior to the study provides the look-up tables that are used to convert the ratio of the green and red intensity images to global temperature mappings. With temperature images acquired at different times in a wind tunnel run, global heat transfer images are computed assuming one-dimensional heat conduction. The primary advantage of this technique is the global resolution of the quantitative heat transfer data. Such data can be used to identify the heating footprint of complex, three-dimensional flow phenomena (e.g., transition fronts, turbulent wedges. boundary layer vortices, etc.) that are difficult to resolve by discrete measurement techniques. Phosphor thermography is routinely used in Langley's hypersonic facilities because models can be fabricated more quickly and economically than other techniques, and the method provides quantitative global information. Recent comparisons of heat transfer measurements obtained from phosphor thermography to conventional thinfilm resistance gages measurements (Merski 1998) and to CFD predictions (Hollis, et al. 1999. Berry, et al. 1999a, Loomis, et al. 1997, Hamilton, et al. 1998 and Horvath, et al. 2000) have shown good agreement.

Flow visualization techniques, in the form of schlieren and oil-flow, were used to complement the surface heating tests. The LaRC 20-Inch Mach 6 Air Tunnel is equipped with a pulsed white-light, Zpattern, single-pass schlieren system with a field of view encompassing the entire 20 -in test core. The LaRC. 31-Inch Mach 10 Air Tunnel does not currently have a schlieren system. Tsai and Bakos (1998) describe the HYPULSE schlieren system. The schlieren images from both the 20-Inch Mach 6 and HYPULSE tunnels were recorded with a highresolution digital camera. Surface streamline patterns 
were obtained using the oil-flow technique. The metal model was spray-painted black to enhance contrast with the white pigmented oils used to trace streamline movement. Surface streamline development was recorded with a conventional video camera, while post-run digital photographs were recorded with a high-resolution digital camera.

For the test conducted at HYPULSE, thin-film resistance gages were used to provide the heat transfer distributions. Thin-film gages, constructed of nickel and copper deposited on a thin polymide film and then bonded to the surface of model inserts (similar to the thin-film technique described by Berry and Nowak, 1997b), were used to measure surface temperature-time histories at roughly 140 locations over the Hyper-X forebody. These sensors were arranged in 3 length-wise rows, one on centerline and the others 1.5-in on either side of centerline, as well as several span-wise rows to look for flow nonuniformity behind the trips. The polymide film was 0.002 -in thick and, based on the test-time (a few milli-seconds), was thick enough to be treated as semi-infinite for data reduction purposes. The nickel sensors, 0.002 -in wide by 0.100 -in long, were connected to nickel and copper leads which were routed to the back side of the inserts and internally wired (within the model and support system) through to the facility connections.

\section{Model Description}

A sketch of the $33 \%$ scale Hyper-X forebody model is shown in Fig. 4 . Note that the chines of the forebody model were laterally truncated aft of the first ramp-corner in order to minimize tunnel blockage and to isolate the model within the tunnel test core. A numerically controlled milling machine was used to build the forebody model with a detachable stainless-steel leading edge and interchangeable measurement surface inserts as well as various stainless-steel trip and inlet configurations. Although a majority of the forebody (the strongback) was constructed from aluminum to save weight, the leading edge was machined from stainless steel with a nose radius of 0.010 -in to allow replacement if damaged. The length of the leading edge was selected to be 5 -in in order to provide for adequate thickness for attachment to the aluminum strongback. The trip station was another 2.418-in aft of the leading edge attachment point (for a total length from the model leading edge of 7.418-in). The interchangeable trip configurations were designed and sized based on the local flow properties at this forebody station. The remaining flat ramp sections were designed to accommodate both a Macor and an aluminum set of inserts. Macor is a machinable glass ceramic and is a registered trademark of Corning Incorporated. The engine inlet sidewalls were made of stainless steel and were designed to accommodate both open and closed engine cowl door configurations. The open configuration represents the forebody at test point with the engine cowl door in the operating position, although for the wind tunnel model the cowl is removed to provide optical access to the internal flat ramp surface. Figure $5 \mathrm{a}$ is a photograph of the Hyper-X forebody model with the Macor inserts for the phosphor thermography testing in the open-cowl configuration. The closed configuration represents the forebody prior to test point with the engine cowl door in the blocked inlet position. This configuration was tested to investigate the heating effect of the trips on the closed cowl. Figure $5 \mathrm{~b}$ is a photograph of the Hyper-X forebody model with the aluminum inserts for flow visualization testing in the closed-cowl configuration.

Normally a cast ceramic process, which provides accurate replication of entire complex threedimensional configurations, is used to build phosphor thermography models. In this case, precision metal machining was used in lieu of the casting process as a thin high-fidelity leading edge and interchangeable trip configurations were required. As the ramp sections behind the trip location were planar across a majority of the span, 0.25 -in thick flat sheets of Macor were used for the phosphor substrate. The Macor substrates were coated with a mixture of phosphors suspended in a silica-based colloidal binder. This coating consisted of a 5:1 mixture of lanthanum oxysulfide ( $\left.\mathrm{La}_{2} \mathrm{O}_{2} \mathrm{~S}\right)$ doped with trivalent europium and zinc cadmium sulfide ( $\mathrm{ZnC}$ (dS) doped with silver and nickel. The coatings typically do not require refurbishment between runs in the wind tunnel and are approximately 0.001 -in thick. The final step in the fabrication process was to apply fiducial marks along the body to assist in determining spatial locations accurately. The fiducial marks used for the present study werc the joints between the Macor inserts, which correspond to the location of the ramp angle changes shown in the skelch in Fig. 4 .

The five trip configurations were sized based on flow conditions for the 31-Inch Mach 10 Air Tunnel with the trip height $(\mathrm{k})$ as the primary variable. Trip 1 (Fig. 3a) is a row of squares rotated 45 -deg to the flow with spacing roughly equal to the width of each trip. This configuration was designed in two pieces with the trips protruding through holes in the base plate. Various thickness spacers provided the 
required variability in trip height. Trip 2a (Fig. 3b) and Trip 2b (Fig. 3c) are similar in concept, both essentially ramped wedges, where the wedge orientation is reversed from convention (wedge tip pointing aft) and the ramp starts at the model surface at the front of the trip and rises to the aft tip. These configurations generate half the number of vortices per unit-VG of Trip 1, thus the spacing between the trips was removed in order to double the number of trips and vortices. The Trip 2 a configuration held the length and width of the trip constrained, so the ramp angle increased as the trip height increased. The Trip $2 \mathrm{~b}$ design held the width and ramp angle of the trip constrained. so the length of the trips increased as the trip height increased. Midway through the test series a modification to Trip $2 b$ was suggested, which truncated the sharp aft end (thus providing a blunt base), and this trip design was designated as Trip 2c (Fig 3d). The blunt base was selected to be a fourth as wide as the leading edge and was hoped to provide for increased vortex strength. Trip 3 (Fig 3e) is a conventional ramped wedge. which has a blunt base facing aft, that held the length and width of the trip constrained, so the ramp angle increased as the trip height increased. Because of the blunt base, the spacing for Trip 3 was the same as Trip 1. Six fixed heights $(\mathrm{k}=0.015,0.030,0.045,0.060,0.090,0.120$ in) were constructed for Trips 2a. 2b, 2c, and 3.

Figure 6 shows a photograph of the thin-film instrumented Hyper- $X$ forebody model installed in HYPULSE. As shown in the figure, the three inserts representing the flat ramps prior to the inlet were each instrumented with a nearly identical pattern of gages, providing over 140 measurement locations. As stated earlier, the sensor leads, which are the most obvious features on each insert, were routed on the surface to the internal cavity of the model and then connected to the tunnel data acquisition system. Five sets of thin-film inserts were fabricated ( 15 total) for use during the test series. The inserts were periodically replaced (typically every 4 to 5 runs) as gage performance was degraded from repeated exposure to post-test debris (material from the rupture of the tunnel diaphragms).

\section{Test Conditions}

Nominal reservoir stagnation and corresponding freestream flow conditions for the present study are presented in Table 2. Flow conditions for the 20Inch Mach 6 Air and 31-Inch Mach 10 Air tunnels were based on measured reservoir pressures and temperatures and recent unpublished calibrations of the facilities. Flow conditions for HYPULSE were based on measured tube and reservoir pressures, shock speeds, and recent calibrations conducted with comparisons to computed nozzle conditions.

\section{Data Reduction and Uncertainty}

For the phosphor data, heating rates were calculated from the global surface temperature measurements using the one-dimensional semiinfinite solid heat-conduction equations, as discussed by Buck (1991) and Merski (1998). Based on Merski (1998), phosphor system measurement error is a function of the surface temperature of the model and is typically quoted as 8 to $10 \%$ for the 20 -Inch Mach 6 tunnel and 7 to $10 \%$ for the 31-Inch Mach 10 tunnel, with overall experimental uncertainty of $\pm 15 \%$. The slightly higher uncertainty for the 20 Inch Mach 6 is due to the relatively low temperature driver of the facility that results in lower overall surface temperature rise during a typical tunnel run. As will be shown in subsequent images, a noticeable scatter in the Mach 6 heating images, as compared to similar Mach 10 images is evidence of this increased error. Global heating images are presented in terms of the ratio of heat-transfer coefficients $h / h_{\text {ref }}$, where $\mathrm{h}_{\mathrm{ref}}$ corresponds to the Fay and Ridell (1958) stagnation-point heating on a sphere with radius 4.0in (a 1 -ft radius sphere scaled to the model size). Repeatability of centerline heat transfer distributions was generally better than $\pm 4 \%$.

For the thin-film data, heating rates were calculated from the individual temperature-time histories using the one-dimensional semi-infinite solid heat-conduction equations, as discussed by Cook and Felderman (1966). The sensors were calibrated prior to the test by placing the inserts in an oil bath that was slowly heated and cooled (over a range of temperatures to which the sensors would be exposed during a typical run) while the voltage across the sensors was monitored. The change of resistance of a sensor was assumed to be a linear function of temperature, which provides for a $\pm 3 \%$ accuracy. Both model and facility data were sampled at $200 \mathrm{kHz}$ for $20 \mathrm{~ms}$. The voltage-time histories were recorded and converted to temperature-time histories, based on the previous linear calibrations, and then integrated for each sensor to compute the heating rate. The heating rates presented were time averaged over a window of steady tunnel flow. For the current data, this averaging window begins approximately $2-\mathrm{ms}$ after the passage of the starting shock and has a t-ms duration. Run-to-run repeatability, comparing heating rates from runs at the same flow conditions using the same thin-film 
inserts as well as different inserts, revealed nondimensional laminar heating rates to agree generally within $\pm 8 \%$. Facility flow properties measured during the lesting varied by less than $\pm 2 \%$. Based on these considerations, the total uncertainty in the measured heating is believed to be better than $\pm 15 \%$.

\section{Computational Methods}

Computational Fluid Dynamics (CFD) was used to support the various wind tunnel tests and also to scale the selected trip design for the flight vehicle. As the lower forebody surface flowpath is intended to provide a nominally two-dimensional (2D) inflow into the scramjet inlet, only 2D computations were performed. All computations assumed perfect gas chemistry. Pre-test predictions of laminar and turbulent heating rates based on nominal wind tunnel flow conditions for the scaled forebody were obtained from a boundary layer code (Anderson. 1971). These predictions were used for quick comparison with the experimental data. Also, Anderson's code was used to estimate the effect of trajectory and wall temperature dispersions on scaling the final Mach 7 trips. A NavierStokes/Parabolized Navier-Stokes approach with GASP (Godfrey. 1996) was also used to provide laminar and turbulent heating levels to estimate the onset of transition in the data, and was in reasonable agreement with the boundary layer results. The Baldwin-Lomax turbulence model was used in the turbulent computations (see Baldwin and Lomax, 1978). The GASP solutions also provided estimates of the boundary layer thickness and edge Mach number at the trip location. As shown in Fig. 3, the trip geometry is scaled by the local boundary layer thickness. With a coupled inviscid/viscous solution, the boundary layer edge is defined using the total enthalpy (Bertin, 1994) based on the first point of the surface where the total enthalpy is $99.5 \%$ of its freestream value. This definition of boundary layer edge is also used for scaling the selected trip configuration to the flight vehicle. The boundary layer thickness $(\delta)$ and edge Mach number predictions $\left(M_{e}\right)$ for the LaRC facilities and the HYPULSE RST are given in Table 3, along with the corresponding flight values of these parameters. The CFD solutions of the scaled model assumed a constant wall temperature of $540^{\circ} \mathrm{R}$ for the wind tunnel tests, due to the relatively short run times. However, the flight vehicles will have an axially varying wall temperature due to the carbon-carbon leading edge and tungsten block forebody. This temperature variation has been modeled in the CFD for the flight cases.

\section{Discussion of Results}

Nine separate entries into 3 wind tunnels have been conducted over 3 years producing over 350 runs. Parametrics include the effect of angle-ofattack, Mach number, and Reynolds number for the 5 trip configurations with the inlet door simulated in both the open and closed configuration. In order to limit the scope of the present paper, the results to be presented will be for the wind tunnel cases which most closely match the nominal Mach $7 \mathrm{flight}$ case of $\alpha=2$-deg, $\mathrm{Re}_{\mathrm{L}}=5.6$ million with the inlet door simulated in the open position.

\section{No Trip Baseline}

Figure 7 is a typical baseline (no trip) oil-flow result showing surface streamlines and regions of separation on the Hyper-X forebody for Mach 6 and the nominal wind tunnel condition of $\alpha=2$-deg and $\mathrm{Re}=2.2 \times 10^{6} / \mathrm{ft}$. These results suggest a laminar boundary layer (which will be confirmed in a subsequent section) over most of the forebody due to the onset of separation just prior to the end of both the first and second ramps. These separated flow regions, which appear relatively two-dimensional over the width of the flat ramps. merge with a separated or low shear region, which run the length of the chines, to generate a chine vortex emanating from the compression ramp corners. Based on an analysis of Fig. 7 and other repeat oil-flows, the surface streamlines indicate flow spillage off the flat ramps, with as little as a third of the surface streamlines at the end of the first ramp being captured by the inlet. These results tend to support the earlier concerns regarding flow separations and mass capture. Oil-flow results obtained in the Mach 10 tunnel (not shown) were similar to those obtained at Mach 6. Figure 8 is a baseline phosphor heating image for Mach 6 that has been scaled to fit within a sketch of the model, in order to illustrate the location of the phosphor-coated inserts. The heating results show the first two ramps to be laminar (as will be demonstrated subsequently with comparison to the computations), with transition onset occurring on the last ramp. Similar results are found for the nominal case in Mach 10, shown in Fig. 9. As discussed earlier, natural transition onset just prior to the end of the first ramp minimizes flow spillage and provides a turbulent boundary layer for the inlet. Thus, even in the noisy environment of conventional (non-quiet) hypersonic wind tunnels, forced transition via tripping is required at the nominal conditions. 


\section{Mach 6 Trips}

For Trip 1 at Mach 6 and the baseline condition $\left(\alpha=2-\mathrm{deg}\right.$ and $\left.\operatorname{Re}=2.2 \times 10^{6} / \mathrm{ft}\right)$, the effect of increasing the trip height $(\mathrm{k})$ provides a systematic forward movement of the onset of transition from just inside the inlet to the beginning of the Macor inserts, as shown in Fig. 10. The heating profiles are extracted from the phosphor data along the model centerline and compared to the laminar and turbulent GASP computations. The laminar data on the first ramp is slightly more than $20 \%$ lower than the laminar predictions. perhaps due to the very low temperature rise on the first ramp under laminar conditions. The turbulent data on the first ramp as well as the laminar data on the second ramp compare much more favorably to the predictions. The predictions are mainly intended for estimation of transition onset. The first trip height that, when compared to the no trip case, just begins to affect the location of transition, the so-called incipient ${ }^{2}$ trip height is $k=0.015$-in. By $k=0.030$-in, a significant forward movement of transition (a critical value) onto Ramp 2 is evident. Increasing the trip height further, transition begins to appear on Ramp 1. providing an effective trip height of $\mathrm{k}=0.060$-in. By the largest trip height, $k=0.120$-in, fully turbulent conditions appear at the beginning of the Macor insert. Figure 11 provides representative heating images showing the global movement of transition and the streaks that represent the organized vorticity. Note the relative consistency of the vortices across the span of Ramps 1 and 2 and that the streaks appear to persist through the turbulent regions of Ramps 2 and 3. The results from Trip 3 (not shown) closely resembled Trip 1 in both effectiveness and strength of vortices. Using the calculated boundary layer thickness for the Mach 6 tunnel (shown in Table 3), $(\mathrm{k} / \delta)_{\mathrm{inc}}=0.185,(\mathrm{k} / \delta)_{\mathrm{cr}}=0.37$, and $(\mathrm{k} / \delta)_{\mathrm{eff}}=0.74$ are obtained.

Trips $2 \mathrm{a}, 2 \mathrm{~b}$, and $2 \mathrm{c}$ provided similar results as Trip 1 and 3 but without evidence of strongly organized vorticity in either the laminar or turbulent regions. Of the three. Trip $2 \mathrm{c}$ appeared to be the one that performed nearly as well as Trip 1 (although the differences between the three were very slight) and

\footnotetext{
2 Note that the terminology used here is similar to the definitions of Bertin, et al. (1982). Incipient identifies the maximum roughness height that has little effect on the onset of transition. Critical identifies the roughness height that first begins to move transition rapidly towards the nose. Effective identifies the minimum roughness height that establishes transition onset just downstream of the roughness element.
}

therefore will be shown. Figure 12 provides the effect of varying trip height for Trip 2c at Mach 6 for the nominal condition of $\alpha=2-\mathrm{deg}$ and $\mathrm{Re}=$ $2.2 \times 10^{6} / \mathrm{ft}$. Note that Trip $2 \mathrm{c}$ has about the same values of incipient and critical trip heights as Trip 1. Also, for the largest trip height tested, $k=0.060$-in. the onset of transition for Trip $2 \mathrm{c}$ is about the same as shown for Trip 1. Figure 13 provides the global images for Trip $2 \mathrm{c}$, which shows that the transition fronts are very similar to Trip 1 but without the strongly organized and persistent vorticity.

The oil-flow results are consistent with the trends provided by the phosphors. The addition of the trips to the forebody provides streamwise vorticity within the boundary layer that tends to diminish the separated regions at the end of the compression ramps. Figure 14 provides a comparison of the oilflow results for two different trip heights for Trip 1 at Mach 6 for the nominal conditions. For $k=0.030$-in (Fig. 1 ta), the separation zone at the first ramp corner persists, while the second separation has been removed by the onset of transition on the second ramp. For $k=0.060$-in (Fig. $14 \mathrm{~b}$ ), the trip is now large enough to force transition onset to the first ramp (as per Fig. 10) and thus removes both separations. Unfortunately, oil-flows have not been obtained for the Trip $2 c$ configuration. but the results with Trip $2 b$ showed similar results to those of Trip 1. Also, as the flow separations are removed, the surface streamlines indicate reduced spillage off the flat ramps (implying improved mass capture). The previous observation regarding the inlet capture of only a third of the surface streamlines on the end of the first flat ramp without trips appears to be improved to about a half with trips. It should be noted that these streamlines only indicate the flow direction near the surface. As the inlet ingests most of the vortices (with the exception of those generated by the two most outboard trips), most of the boundary layer must be traveling in a streamwise direction. Thus the surface streamlines as generated by the oil-flow method are not a good indication of the effective mass capture of an inlet.

\section{Mach 10 Trips}

For Trip 1 at Mach 10 and the nominal condition. the effect of increasing $k$ also provides a steady forward movement of the onset of transition, as shown in Fig. 15. (Note that now the comparisons between the laminar experimental data and predictions are within the experimental uncertainty on the first ramp.) Unlike the Mach 6 results. however, the largest trip height only manages to force 
transition to the beginning of Ramp 2. The first trip height that just begins to affect the location of transition, the incipient trip height is $\mathrm{k}=0.030$-in. By $k=0.060$-in, a significant forward movement of transition (a critical value) onto Ramp 2 is evident. By the largest trip height, $k=0.120$-in, the onset of transition has moved to the beginning of Ramp 2 . The effective value has not been reached for Mach 10 conditions, as transition onset has not moved to the beginning of the Macor insert. Figure 16 provides the representative heating images showing the global movement and organized vorticity. Again, note the relative consistency of the vortices across the span of Ramps 1 and 2 and that the streaks appear to persist through the turbulent regions of Ramps 2 and 3 . Using the calculated boundary layer thickness for the Mach 10 tunnel (Table 3 ), these results provide for $(\mathrm{k} / \delta)_{\mathrm{inc}}=0.24 .(\mathrm{k} / \delta)_{\mathrm{cr}}=0.48$, and $(\mathrm{k} / \delta)_{\text {eff }}>1$.

At Mach 10, Trip 2c provided nearly as good forward movement of transition as Trip 1 and still showed no evidence of strongly organized vortices in either the laminar or turbulent regions. Figure 17 provides the effect of varying trip height for Trip $2 \mathrm{c}$ in Mach 10 at the nominal condition. Note that Trip $2 \mathrm{c}$ has about the same value of incipient as Trip 1, but as the trips get larger. Trip 2c lags Trip 1 slightly in forward movement of transition. At the largest trip height tested, $k=0.120$-in. the onset of transition for Trip $2 \mathrm{c}$ is slightly behind Trip 1 . Figure 18 provides the global images for Trip 2c, which shows that the transition fronts are close to Trip 1 but, again. without the organized vorticity.

Figure 19 provides a comparison of the oil-flow results for two different trip heights for Trips 1 and $2 \mathrm{~b}$ at Mach 10 for the nominal conditions. For Trip 1 at $k=0.060$-in (Fig. 19a), the separation zone at the first ramp corner persists, while the second separation has been removed by the onset of transition on the second ramp. For Trip 1 at $k=0.120$-in (Fig. 19b), the trip is now large enough to force transition onset near enough to the first ramp (as per Fig. 15) to remove both separations. For Trip $2 b$ at $k=0.060$-in (Fig. 19c), the separations closely resemble the Trip I results for the same height. For Trip $2 b$ at $k=0.120$ in (Fig. 19d), the trip is almost large enough to remove both separations. Unfortunately, oil-flows have not been obtained for the Trip $2 c$ configuration.

\section{HYPULSE Trips}

The HYPULSE test was conducted to not only provide transition data from a different type facility (and therefore a different noise environment), but also to investigate trip effectiveness at wind tunnel conditions matching both the Mach number and enthalpy for the Mach 7 flight. Tests were conducted for a range of Reynolds numbers at both Mach 6.5 and 7.3 , but only the Mach 7.3 results will be presented as the tunnel flow conditions are more representative of the nominal Mach 7 flight condition. The highest $\mathrm{Re}$ at Mach 7.3 (which provided a matching $\operatorname{Re}_{\mathrm{L}}$ to the Mach 7 flight) resulted in degraded performance for too many thinfilm gages per run, so the decision was made to conduct a majority of the test at the moderate Reynolds number condition of $\operatorname{Re}=1.4 \times 10^{6} / \mathrm{ft}$. The effect of trip height for both Trips 1 and $2 \mathrm{c}$ for the HYPULSE nominal condition is shown in Fig. 20. The heating profiles are from the thin-film results along the model centerline and are compared to laminar and turbulent GASP computations, and are within the experimental uncertainty. Both Trip I and $2 \mathrm{c}$ provide forced transition enhancement similar to the results obtained from the Mach 6 tunnel. Figure 21 shows a schlieren image at Mach 7 in HYPULSE for Trip $2 \mathrm{c}$ and $\mathrm{k}=0.030$-in. The strength of the shocks from the leading edge and ramp corners can be compared to the weak shock emanating from the trip. Based on these results and the calculated boundary layer thickness for HYPULSE (Table 3), $(\mathrm{k} / \delta)_{\mathrm{inc}}=0.20,(\mathrm{k} / \delta)_{\mathrm{cr}}=0.40$, and $(\mathrm{k} / \delta)_{\mathrm{eff}}=0.80$ are obtained.

\section{Flight Design}

Based on the results presented, the Trip 2c design was selected for the Mach $7 \mathrm{flight}$ due to the lack of entrained vorticity within the induced turbulence, without significant loss of transition enhancement. While Trip 1 had a slight tripping efficiency advantage, especially at the higher Mach numbers, the persistent vortices are a concern for providing a non-uniform flow-field for the inlet, as well as localized hot spots for the closed cowl prior to test point. Also, the Trip $2 \mathrm{c}$ configuration was considered to be superior from a structural/thermal viewpoint due to the lack of a blunt face. The thermal survivability during the flight of the integrated hardware (trips, vehicle. and engine) is of primary concern; hence, the trips and surrounding area were thermally assessed (see Cuda 1999 and 2000), and found to be acceptable. Also, there is an on-going effort to thermally assess the impact of the latest trip design on the closed-cowl.

In order to excite the first-mode instabilities, an edge Mach number of less than four is thought to be the best location for placement of the trips for transition enhancement (Reshotko, 1976). Only the 
tests in the LaRC 20-Inch Mach 6 Air Tunnel satisfy this criterion. The HYPULSE test provided an $\mathrm{M}_{\mathrm{e}}=$ 4.2 at the trip location. but the results suggest forcedtransition enhancement similar to the 20-In Mach 6 trends. On the other hand, the LaRC 31-In Mach 10 Air Tunnel provided an $\mathrm{M}_{\mathrm{e}}=4.4$ at the trip location and an effective trip was not identified at a height within the boundary layer. Perhaps for $M_{e}=4.5$ or greater. trips much larger than the boundary layer are required to force transition onset to the trip location. Because of manufacturing limitations, the flight trips are expected to be located at the same axial location for both the Mach 7 and Mach 10 flight vehicles yielding edge Mach numbers of 3.5 and 4.5 . respectively. While confidence is high for adequate trip performance on the Mach 7 flight vehicle, the Mach 10 vehicle might require a relaxation of the requirement to trip the forebody flow close to the trip (to minimize the noise issue) and to force transition onset prior to the first ramp break (to reduce potential flow spillage). The alternative for the Mach 10 vehicle would be to investigate trips on the scale of the boundary layer or larger. Based on the current data, a $\mathrm{k} / \mathrm{\delta}=0.6$ appears adequate to bring transition onset onto the first ramp for the Mach 7 vehicle.

Wall temperature effects are also an important consideration in interpreting the wind tunnel results and making recommendations for flight. For the Mach 7 flight, the varying wall temperature over the tungsten-block first ramp and shuttle-like thermal protection system (TPS) tiles on the second and third ramps provides wall-to-total temperature ratios $\left(\mathrm{T}_{w} / \mathrm{T}_{1}\right.$ ) of roughly 0.26 and 0.39 to 0.52 , respectively. The Mach 6. Mach 10, and HYPIILSE facilities provided relatively uniform $T_{w} / T_{1}$ of $0.55,0.28$, and 0.14 , respectively, which more than covers the range expected in flight. The only region that is not covered is the carbon-carbon leading edge which is expected to provide $T_{w} / T_{1}$ near 0.7 in flight.

Natural transition results were not drastically affected by the different facilities or wall-to-total temperature ratios, which suggests that tunnel noise and wall temperature effects will not have a significant impact on scaling the selected trip design to flight. On the other hand, freestream Mach number provided a systematic change in the incipient, critical, and effective values of $k / \delta$. Between Mach 6 and Mach 7.3, there was an 8\% increase in the incipient, critical. and effective values of $\mathrm{k} / \mathrm{d}$. Between Mach 6 and Mach 10, there was a $30 \%$ increase in the incipient and critical value of $k / \delta$.
The current approach for scaling to flight is based on $k / \delta$ while including an assessment of the forebody boundary layer thickness for expected variations of the vehicle trajectory, angle-of-attack. and wall temperature in flight. Current dispersions on the Mach 7 flight calls for $\alpha=2-\mathrm{deg} \pm 1$-deg and wall temperatures between 1000 and $1500^{\circ} \mathrm{R}$. A maximum and minimum boundary layer thickness were computed from these dispersions and determined to be $\delta_{\max }=0.205$-in and $\phi_{\min }=0.173$-in. A trip height of $k=0.125$-in provides an acceptable coverage of between $60 \%$ to $70 \%$ of the boundary layer. This range is deemed adequate to force transition in a reasonably short distance behind the trip, while not excessively enhancing the integrated closed-cowl heat load. Additional details are provided by Dilley (1999). Figure 22 provides a close-up photograph of the Trip 2c sized for flight and installed on a full scale, prototype enginevehicle, which has been ground tested at the Mach number and enthalpy matching the Mach 7 flight with successful results, see Huebner (2000). The instrumentation lay-out for the Mach 7 Hyper-X forebody is shown in Fig. 23, which will be used post-flight to assess the forced-transition results. A successful flight will provide an unique opportunity to verify the trip design and the method by which the trip design was scaled to flight.

\section{Conclusions}

An experimental investigation of the boundary layer trip effectiveness and the effect of the trips on the aeroheating characteristics for a $33 \%$ scale Hyper-X forebody model has been conducted in the 20-Inch Mach 6 Air Tunnel, the 31-Inch Mach 10 Air Tunnel, and the HYPULSE RST Tunnel at GASL. These facilities provided an adequate range of the Mach numbers, length Reynolds numbers, and enthalpies to allow proper duplication of Mach 7 flight conditions. Phosphor thermography and thinfilm resistance gages were used to provide heat transfer distributions, and transition onset locations, for a variety of angles-of-attack and Reynolds numbers with discrete roughness elements, which included several trip configurations and heights. The aeroheating results were complemented with oil-flow images that provided surface streamline information and schlieren images that provided shock wave details. These results were used to select a final trip configuration and height for the Mach 7 flight vehicle.

Five trip configurations were screened and the results indicated that all provided adequate transition 
enhancement. The final trip configuration was selected based on a minimization of entrained vorticity within the turbulent region and consideration of the thermal survivability of the trip. Facility noise. wall-to-total temperature ratios, and enthalpy effects did not significantly influence the results. Also, freestream Mach number did not affect the natural transition results, but did have a systematic influence on the forced-transition results. An effective trip height to boundary layer thickness ratio of 0.6 was selected to provide transition onset prior to the end of the first ramp for the Mach 7 flight. The final trip design was sized based on considerations of variations of the trajectory, angleof-attack, and forebody temperature and resulted in a trip height of 0.125 -in.

\section{Acknowledgment}

This experimental effort was accomplished with the help of many dedicated individuals. a few of which are mentioned here. The trip configurations were selected with the assistance of an ad hoc hypersonic boundary layer transition panel, which included G. Anderson, P. Drummond, A. Kumar, M. Malik, and C. Street. Additional CFD computations were supplied by G. Mekkes. A. Frendi, and T. Jentink. The model was built with the help of $W$. Kimmel. K. Meidinger, G. Draughon, M. Powers. M. Griffin. and J. Bartlett. LaRC testing was accomplished with the support of J. Ellis, R. Manis, G. Gleason, B. Senter, G. Bittner, and R. Merski. GASL testing was assisted by R. Bakos, C. Tsai, E. Poole, and R. Perez.

\section{References}

Anderson EC. Lewis CH. 1971. Laminar or Turbulent Boundary-l ayer Hlows of Perfect Gases or Reacting Gas Mixtures in Chemical Equilibrium. NASA CR-1893

Bakos R. Calleja J, Erdos J. 1996a. An Experimental and Computational Study I eading to New Test Capabilities for the HYPULSE Facility with a Detonation Driver. $A / A A$ Paper 96-2193

Bakos R. Castrogiovanni A, Calleja J, Nucci L, Erdos J. 1996b. Expansion of the Scramjet Ground Test Envelope of the HYPIILSE Facility. AIAA Paper $96-4506$

Baldwin BS. Lomax H. 1978. Thin-Layer Approximation and Algebraic Model for Separated Turbulent Flows. AIAA Paper 78-0257

Berry SA. DiFulvio M. Kowalkowski MK. 2000a. Forced Boundary Layer Transition on $X-43$ (Hyper- $X$ ) in NASA LaRC 31 -Inch Mach 10 Air Tunnel. NASA/TM-2000-210315
Berry SA. DiFulvio M, Kowalkowski MK. 2000b. Forced Boundary Layer Transition on X-43 (Hyper-X) in NASA l aRC 20-Inch Mach 6 Air Tunnel. NASA/TM-2000-210316

Berry SA, Horvath TJ. DiFulvio M, Glass C., Merski NR. 1999a. X-34 Experimental Aeroheating at Mach 6 and 10. J. Spacecr. Rockets 36(2): 171-178

Berry SA. Horvath TJ. Hollis BR, Thompson RA, Hamilton HH. 1999b. X-33 Hypersonic Boundary Layer Transition. AlAA Paper 99.3560

Berry SA, Bouslog SA, Brauckmann GJ, Caram JM. 1998. Shuttle Orbiter Experimental Boundary-Layer Transition Results with Isolated Roughness. J. Spacecr. Rockets 35(3): $24 /-248$

Berry SA, Horvath TJ, Roback VE, Williams GB. 1997a. Results of Aerothermodynamic and Boundary-Layer Transition Testing of 0.0362-Scale X-38 (Rev. 3.1) Vehicle in NASA Iangley 20-Inch Mach 6 Tunnel. NASA TM. $1 / 2857$

Berry SA, Nowak RJ. 1997b. Fin Leading Edge Sweep Effect on Shock-Shock Interaction at Mach 6. J. Spacecr. Rockets 34(4): 416.425

Bertin JJ. 1994. Hypersonic Aerothermodynamics. AlAA Education Series, pp.114-117

Bertin JJ, Hayden,TE, Goodrich WD. 1982. Shuttle BoundaryLayer Transition Due to Distributed Roughness and Surface Cooling. J. Spacecr. Rockets 19(5):389-396

Buck GM. 1989. Automated Thermal Mapping Techniques Using Chromatic Image Analysis. NASA TM 101554

Buck GM. 1991. Surface Temperature/Heat Transfer Measurement Using A Quantitative Phosphor Thermography System. AlAA Paper 9/-0064

Calleja JF. 2000. Boundary Layer Transition Experiments on a One-Third Scale Hyper-X Forebody Model at Mach 7 and 10. GASL Technical Report No. 382

Cook WJ, Felderman EJ. 1966. Reduction of Data from ThinFilm Heat-Transfer (iages: A Concise Numerical Technique. AIAA J. 4(3): $561-62$

Cuda V. 1999. Mach 7 Boundary Layer Trip Thermal Analysis. Hyper-X DN 99-003

Cuda V. 2000. Mach 10 Boundary Layer Trip Thermal Analysis. Hyper-X DN 00-006

Demetriades A. 1991. Supersonic and Hypersonic BounadryLayer Transition Induced by Discrete Trips. In FED-Vol 114. Boundary Layer Stability and Transition to Turbulence: 173.78

Dilley AD. 1996. Hyper-X Trip Sizing and Preliminary Drag Estimates. Hyper-X Technical Nore 96HN0064. NASI-19864

Dilley AD. 1999. Final Design for Mach 7 Hyper-X Boundary Layer Trips. Hyper-X Technical Note 99-282, NAS/-96013 
Erdos J, Calleja J, Tamagno J. 1994. Increase in the Hypervelocity Test Envelope of the HYPULSE ShockExpansion Tube. AIAA Paper 94-2524

Fay JA, Ridell FR. 1958. Theory of Stagnation Point Heat Transfer in Dissociated Air. J. Aerosp. Sci. 25(2):73-85,121

Godfrey AG. 1996. General Aerodynamic Simulation Program Version 3.0 User's Manual. Aerosoft, Inc.

Hama FR. 1957. An Efficient Tripping Device. In Readers Forum, J. Of Aero. Sc. Vol. 24: 236-37

Hama FR. 1964. Boundary-Layer Tripping in Super- and Hyper-sonic Flows. In JPL Space Programs Summary No 37-29 Vol. IV: $163-68$

Hamilton HH, Berry SA, Horvath TJ, Weilmuenster KJ. 1998. Computational/ Experimental Aeroheating Predictions for X-33 Phase II Vehicle. A/AA Paper 98-0869

Holland SD, Berry SA, Weidner JP. 1995. Design Methodology and Constraints for the Hypersonic Systems Technology Program (HySTP) Forebody/Inlet Model. NASA TM / $1019 /$

Hollis BR, Horvath TJ, Berry SA. Hamilton HH, Alter SA. 1999. X-33 Computational Aeroheating Predictions and Comparisons with Experimental Data. AlAA Paper 99-3559

Horvath TJ, Berry SA. Merski NR. Fitzgerald SM. 2000. X-38 Experimental Aerothermodynamics. AIAA Paper 2000-2685

Huebner LD, Rock KE, Witte DW, Ruf EG, Andrews EH. 2000. Hyper-X Engine Testing in the NASA Langley 8Foot High Temperature Tunnel. AlAA Paper 2000-3605

Kendall JM. 1975. Wind Tunnel Experiments Relating to Supersonic and Hypersonic Boundary-Layer Transition. AIAA J. 13(3):290-99

Lau KY, Vaporean CN. 1992. Parametric Boundary Layer Transition Study for NASP-like Configuration Using Linear Stability Analyses. Presented at the National Aerospace Plane Mid-term Technology Review. Monterey CA. paper number 283.

Loomis MP. Venkatapathy, E, Davies CB, Campbell CH. Berry SA, Horvath TJ, Merski NR. 1997. Aerothermal CFD Validation and Prediction for the X-38 Program. AlAA Paper 97.2484

Malik MR. 1989. Prediction and Control in Transition in Supersonic and Hypersonic Boundary Layers. AlAA J. 27(1):1487-93

McClinton CR, Holland SD, Rock KE. Englund WC, Voland RT, Huebner LD, Rogers RC. 1998. Hyper-X Wind Tunnel Program. AlAA Paper 98-0553
Merski NR. 1998. Reduction and Analysis of Phosphor Thermography Data with the JHEAT Software Package. AlAA Paper $98-07 / 2$

Micol JR. 1998. Langley Aerothermodynamic Facilities Complex: Enhancements and Testing Capabilities. AIAA Paper 98-0147

Miller CG. 1990. Langley Hypersonic Aerodynamic/Aerothermodynamic Testing Capabilities Present and Future. AlAA Paper 90-1376

Miller CG, Jones JJ. 1983. Development and Performance of the NASA Langley Research Center Expansion Tube/Tunnel, a Hypersonic-Hypervelocity Real-Gas Facility. In Proc. $14^{\text {th }}$ Int. Symp. On Shock Tubes and Waves

Modroukas D, Betti A, Chinitz W, Bakos RJ. 1998. Design. Fabrication, and Calibration of a Mach 6.5 Hypersonic Shock Tunnel Nozzle for Scramjet Testing Applications. AlAA Paper $98-2496$

Owen FK, Hortstman CC, Stainback PC, Wagner RD. 1975. Comparison of Wind Tunnel Transition and Freestream Disturbance Measurements. AIAA J. 13(3):266-69

Rausch VL, McClinton CR, and Crawford JL. 1997a. Hyper-X: Flight Validation of Hypersonic Airbreathing Technology. ISABE Paper $97-7024$

Rausch VL. McClinton CR. Hicks JW. 1997b. NASA Scramjet Flights to Breath New Life into Hypersonics. Aerospace America 35(7): $40-46$

Reshotko E. 1976. Boundary Layer Stability and Transition. Ann. Rev. Fluid Mech. 8:311-49

Reed HL, Kimmel R, Schnieder S, Arnal 1). 1998. Drag Prediction and Transition in Hypersonic Flow. AGARD CP. 600 Vol. 3. C15

Schneider SP. 2000. Effects of High-Speed Tunnel Noise on Laminar-Turbulent Transition. AlAA Paper 2000-2205

Stetson KF. 1990. Hypersonic Transition Testing in Wind Tunnels. In Instability and Transition Vol I, ed. MY Hussaini, RG Voight, 90:91-97. Springer-Verlag

Stetson KF, Thompson ER, Donaldson JC, Siler LG. 1984. Laminar Boundary Layer Stability Experiments on a Cone at Mach 8. Part 2: Blunt Cone. AlAA Paper 84.0006

Tamagno J. Bakos R, Pulsonetti M. Erdos J. 1990. Hypervelocity Real-Gas Capabilities of GASL's Expansion Tube (HYPULSE) Facility. AIAA Paper 90-1390

Tsai CY, Bakos RJ. 1998. Shock-Tunnel Flow Visualization with a High-Speed Schlieren and Laser Holographic Interferometry System. AlAA Paper 98-2700 
Table 1: Hyper-X trip screening tests in NASA facilities.

\begin{tabular}{|c|c|c|c|c|c|}
\hline Year & Tunnel & Test & Occupancy Dates & Runs & Description \\
\hline 1997 & $31-\ln \mathrm{M}-10$ & 338 & Aug 14-Aug 29 & $1-76$ & Phosphor \\
\hline 1997 & $20-\operatorname{In} M-6$ & 6755 & Sept 2 - Sept 5 & $1-61$ & Phosphor and schlieren \\
\hline 1997 & $31-\ln M-10$ & 338 & Sept $30-$ Oct 20 & $77-170$ & Phosphor and oil-flow \\
\hline 1998 & $20-\operatorname{In} M-6$ & 6768 & $\operatorname{Mar} 30-\operatorname{Apr} 2$ & 22 & Oil-flow \\
\hline 1998 & $31-\ln M-10$ & 346 & Apr $6-$ Apr 10 & $1-20$ & Oil-flow \\
\hline 1998 & $31-\ln M-10$ & 349 & Sept 3 - Sept 8 & $1-25$ & Phosphor with new trip \\
\hline 1998 & $31-\ln M-10$ & 351 & Sept 16 - Sept 18 & $1-19$ & Phosphor on closed cowl \\
\hline 1999 & HYPULSE & & Feb 23-Mar 26 & $1-28$ & Thin-film and schlieren \\
\hline 1999 & $20-\ln M-6$ & 6791 & Aug 10 & $1-10$ & Phosphor with new trip \\
\hline 1999 & $20-\ln M-6$ & 6793 & Sept $15-$ Sept 17 & $1-11$ & Phosphor w/ leading edge roughness \\
\hline
\end{tabular}

Table 2: Nominal tunnel flow conditions.

\begin{tabular}{||c|c|c|c|c|c|c|}
\hline Tunnel & $\mathrm{Re}_{*}\left(\times 10^{6} / \mathrm{ft}\right)$ & $\mathrm{M}_{*}$ & $\mathrm{p}_{\mathrm{t}}(\mathrm{psi})$ & $\mathrm{T}_{\mathrm{t}}\left({ }^{\circ} \mathrm{R}\right)$ & $\mathrm{H}_{11}(\mathrm{BTU} / \mathrm{bm})$ & $\mathrm{p}_{\mathrm{t} 2}(\mathrm{psi})$ \\
\hline 20-In Mach 6 & 2.2 & 6.0 & 125.5 & 906.6 & 218.2 & 3.8 \\
\hline 3I-In Mach 10 & 2.2 & 9.9 & 1451.7 & 1808.1 & 454.8 & 4.5 \\
\hline HYPULSE & 1.4 & 7.31 & 1994.3 & 3951.0 & 1079.4 & 18.6 \\
\hline
\end{tabular}

Table 3: Calculated boundary layer parameters at the trip location.

\begin{tabular}{||c|c|c|c|c||}
\hline Tunnel or Flight & $\mathrm{M}_{x}$ & $\mathrm{Re}_{x}\left(\mathrm{x} 10^{\circ} / \mathrm{ft}\right)$ & $\delta(\mathrm{in})$ & $\mathrm{M}_{c}$ \\
\hline 20-In Mach 6 & 6.0 & 2.2 & 0.081 & 3.1 \\
\hline 31-In Mach 10 & 9.9 & 2.2 & 0.125 & 4.4 \\
\hline HYPULSE & 7.3 & 1.4 & 0.075 & 4.2 \\
\hline Mach 7 Flight & 7.0 & 0.9 & 0.180 & 3.4 \\
\hline Mach 10 Flight & 10.0 & 0.6 & 0.283 & 4.5 \\
\hline
\end{tabular}




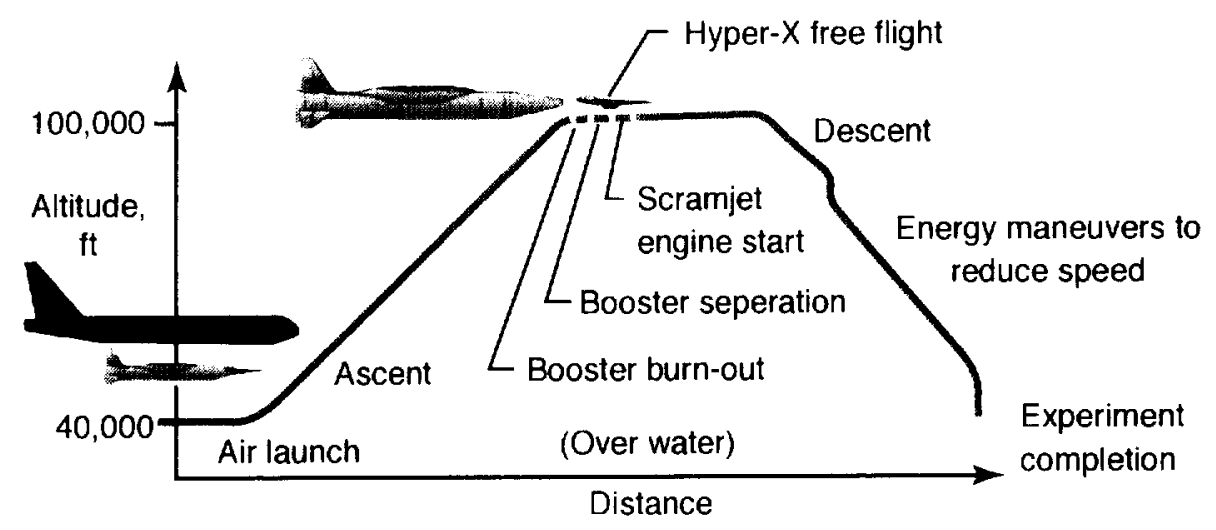

Figure 1a. Preliminary Hyper-X trajectory
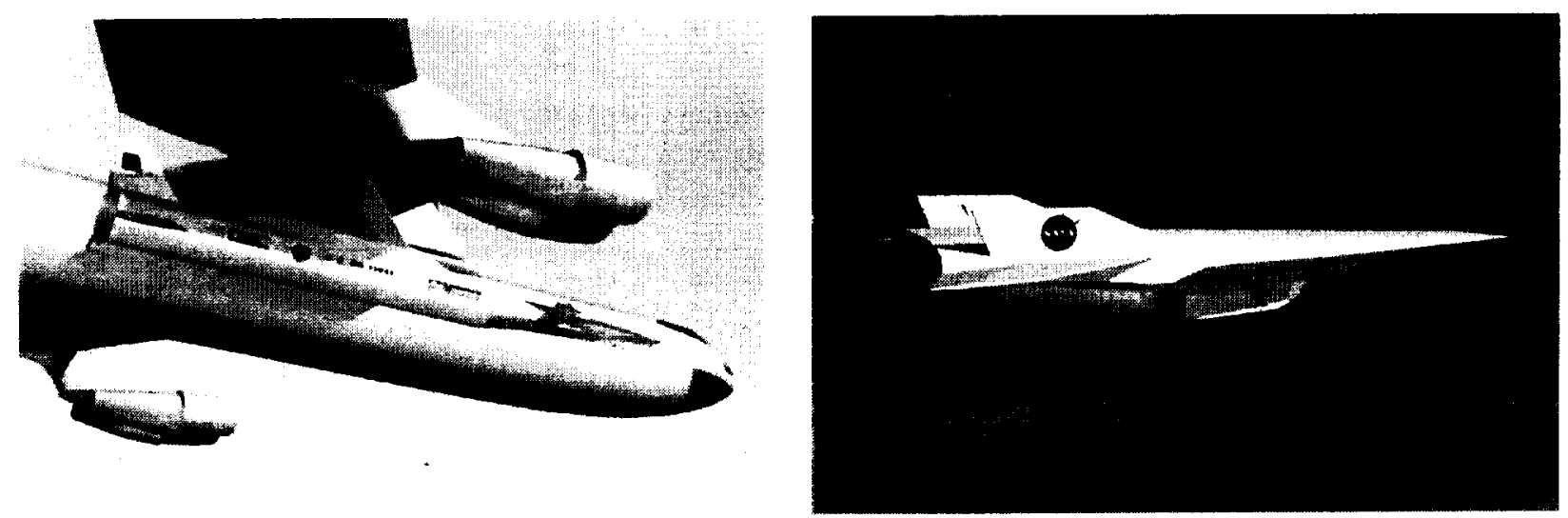

Figure 1b. Hyper-X vehicle mated to Pegasus booster awaiting drop from B-52.

Figure 1d. Hyper-X vehicle flying at test-point.

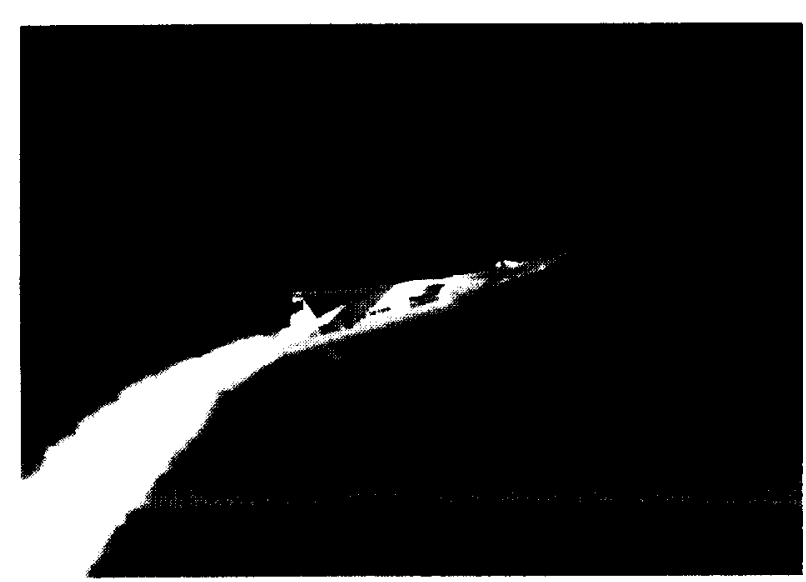

Figure 1c. Hyper-X vehicle lofted to test-point by Pegasus booster.

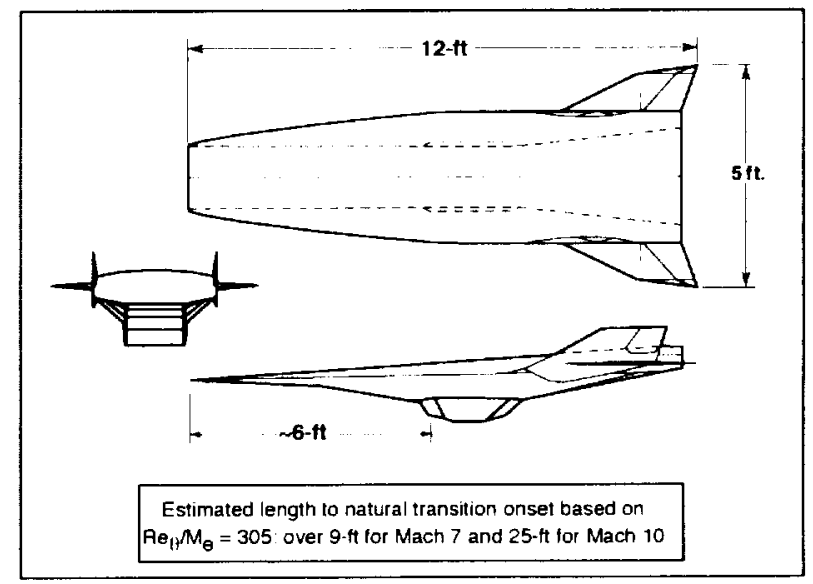

Figure 2. Hyper-X vehicle dimensions. 



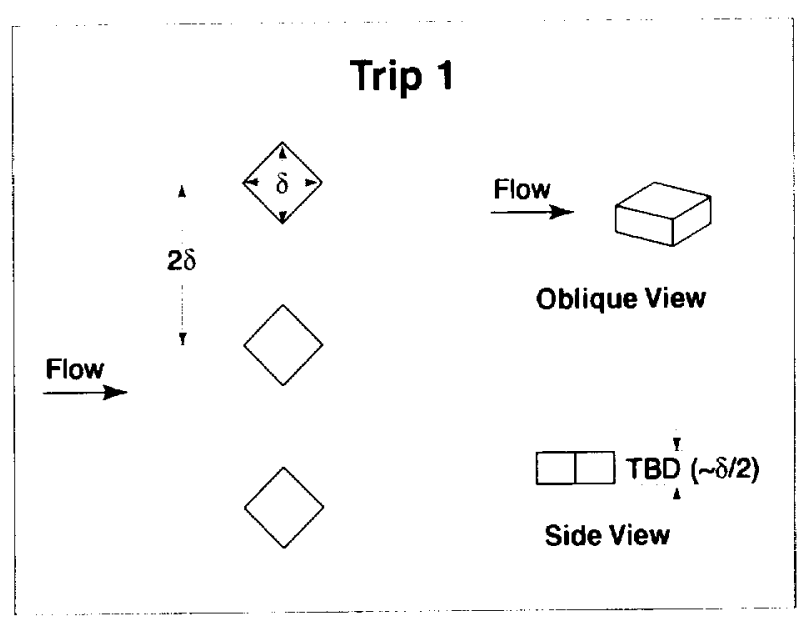

Figure 3a. Baseline boundary layer trip configuration, Trip 1.

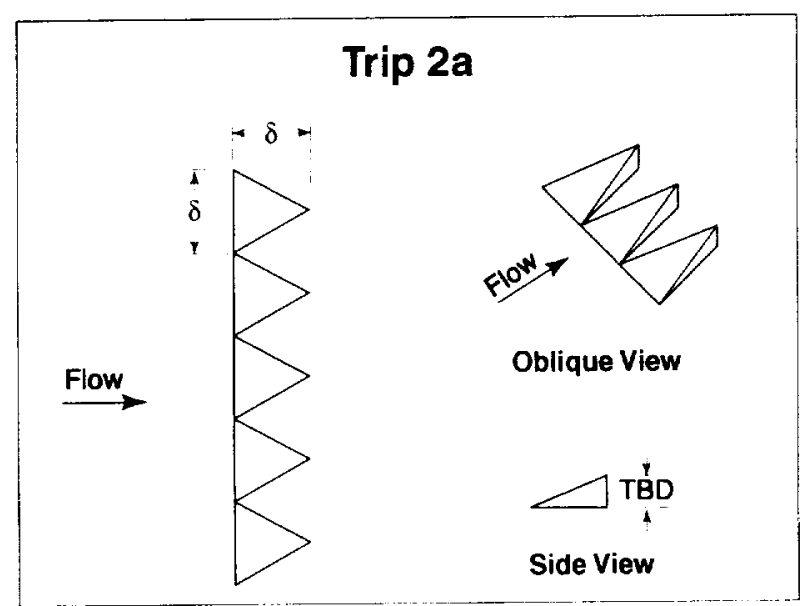

Figure 3b. Original boundary layer trip configuration for screening, Trip $2 a$.

\section{Trip 2b}

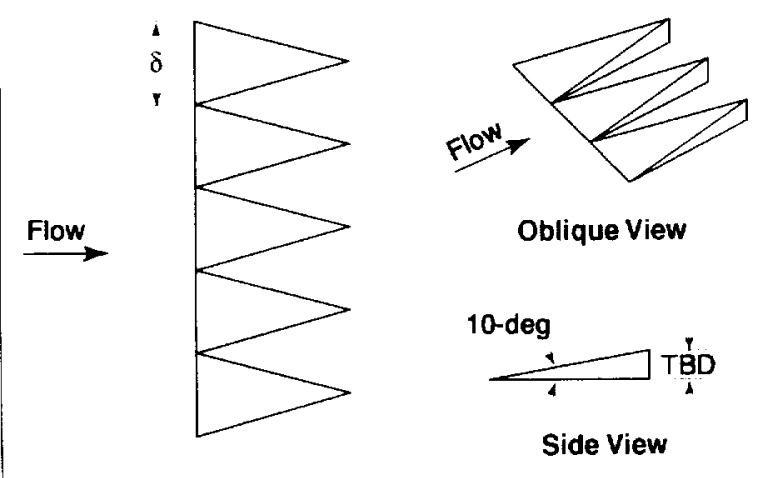

Figure 3c. Original boundary layer trip configuration for screening, Trip $2 b$.

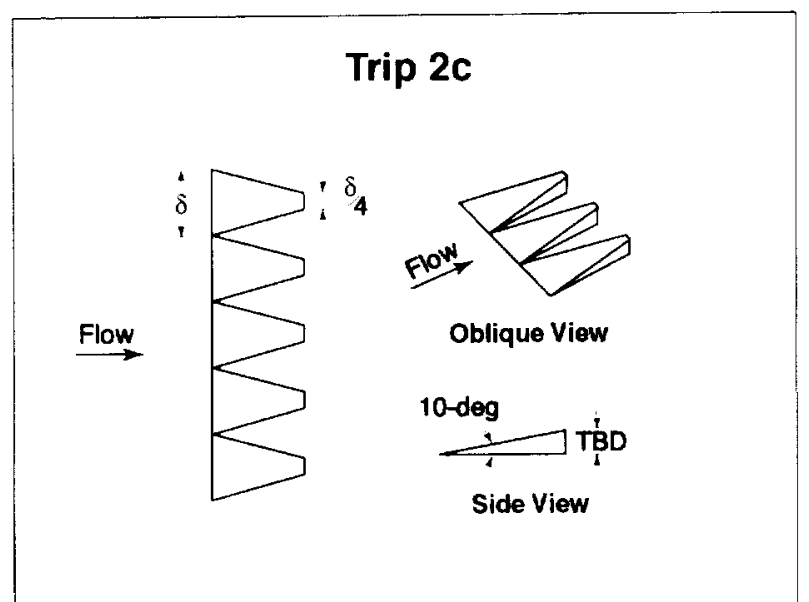

Figure 3d. Additional boundary layer trip configuration for screening, Trip $2 c$.

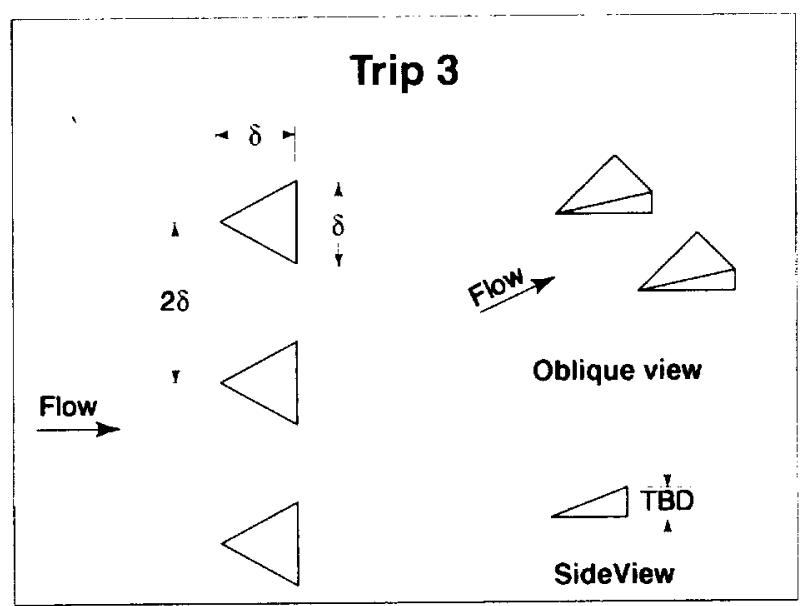

Figure 3e. Original boundary layer trip configuration for screening, Trip 3.

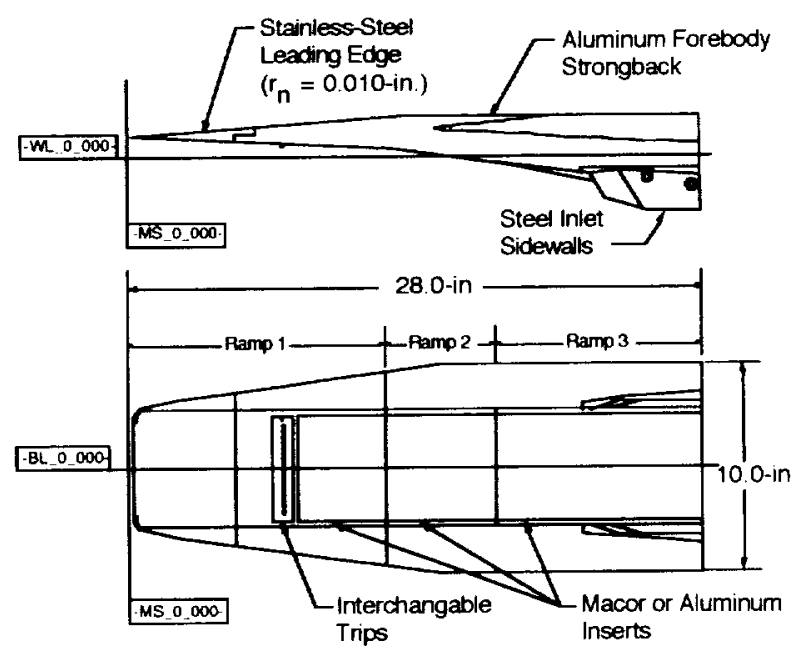

Figure 4. Hyper-X forebody model dimensions. 



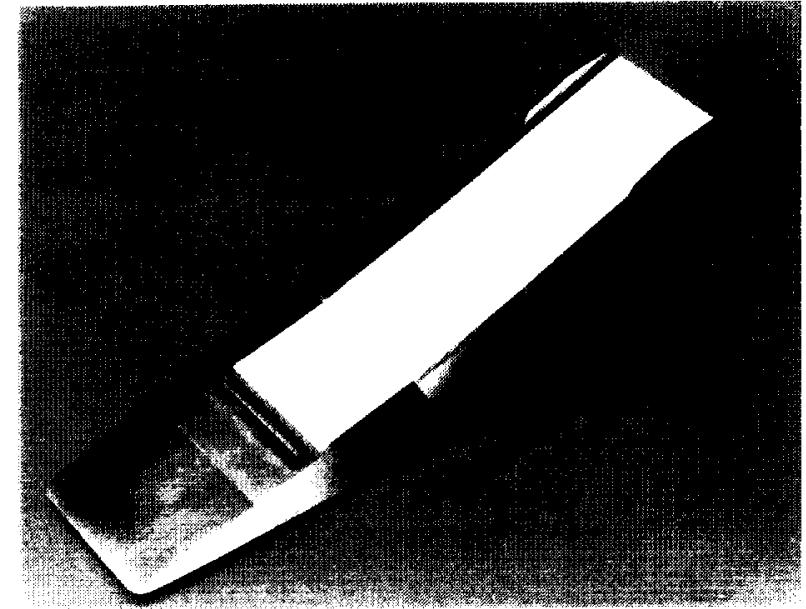

Figure 5a. Photograph of 0.333-scale Hyper-X forebody model in the open-cowl configuration with Macor inserts for phosphor thermography testing.

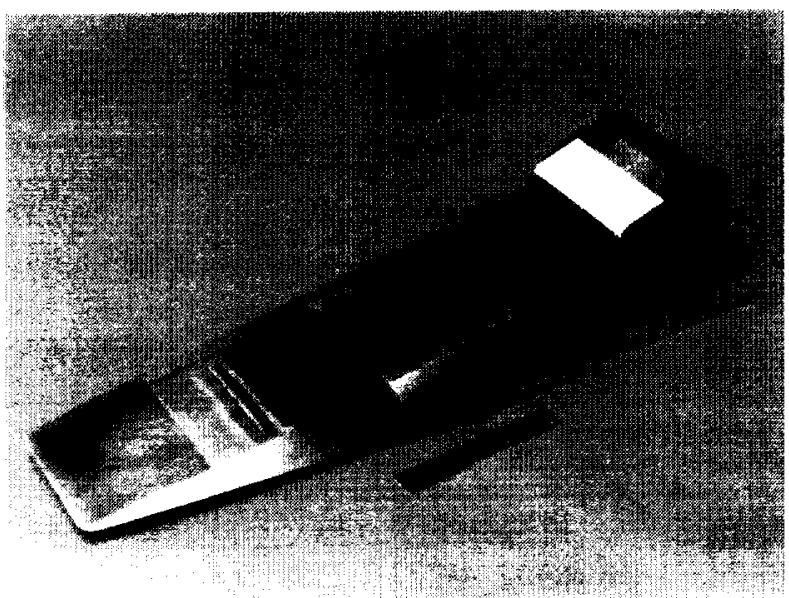

Figure 5b. Photograph of 0.333-scale Hyper-X forebady model in the closed-cowl configuration with metal inserts for flow visualization testing.

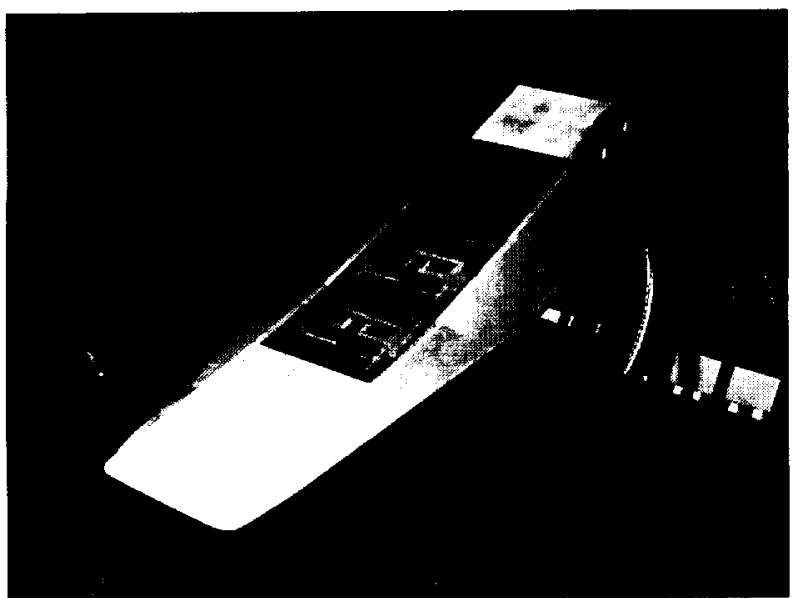

Figure 6. Hyper- $X$ forebody thin-film model installed in HYPULSE.

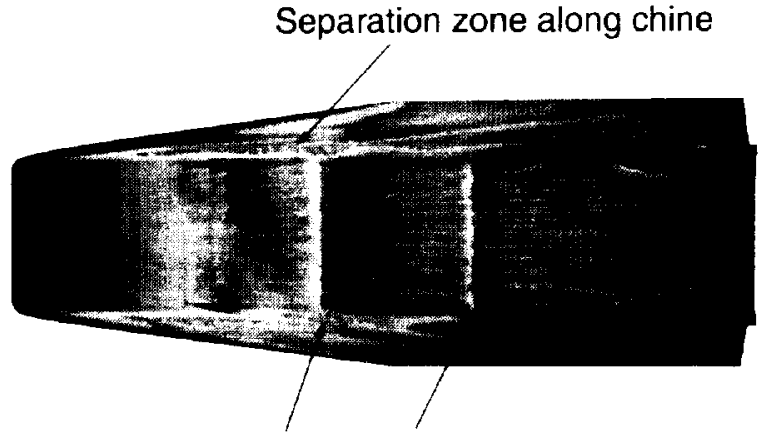

Separations at 1 st and 2 nd corner

Figure 7. Oil-flow on Hyper- $X$ forebody model without trips at Mach 6, $\alpha=2-\mathrm{deg}$, and $\operatorname{Re}=$ $2.2 \times 10^{6} / \mathrm{ft}$.

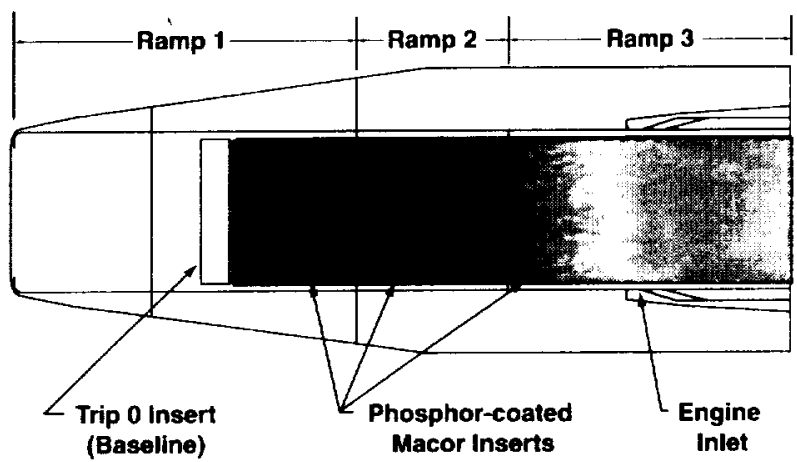

Figure 8. Baseline phosphor heating image scaled to Hyper- $\mathrm{X}$ forebody model, Mach $6, \alpha=2$-deg, $\operatorname{Re}=$ $2.2 \times 10^{6} / \mathrm{ft}$, and no trips.

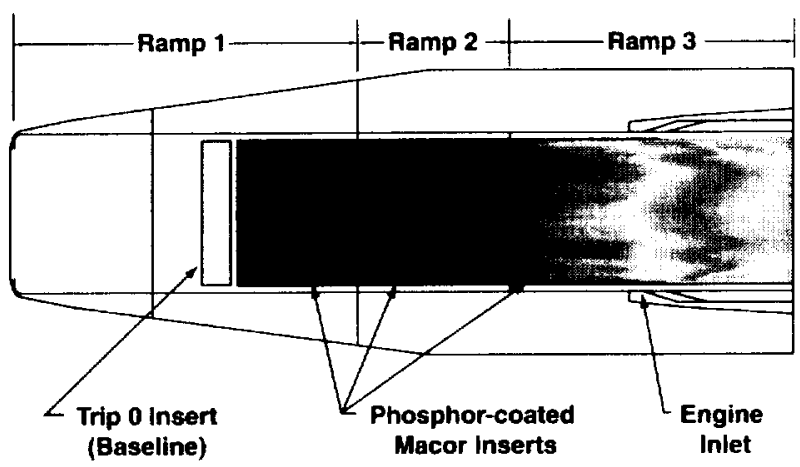

Figure 9. Baseline phosphor heating image scaled to Hyper-X forebody model, Mach $10, \alpha=2$-deg, $\operatorname{Re}=$ $2.2 \times 10^{6} / \mathrm{ft}$, and no trips. 



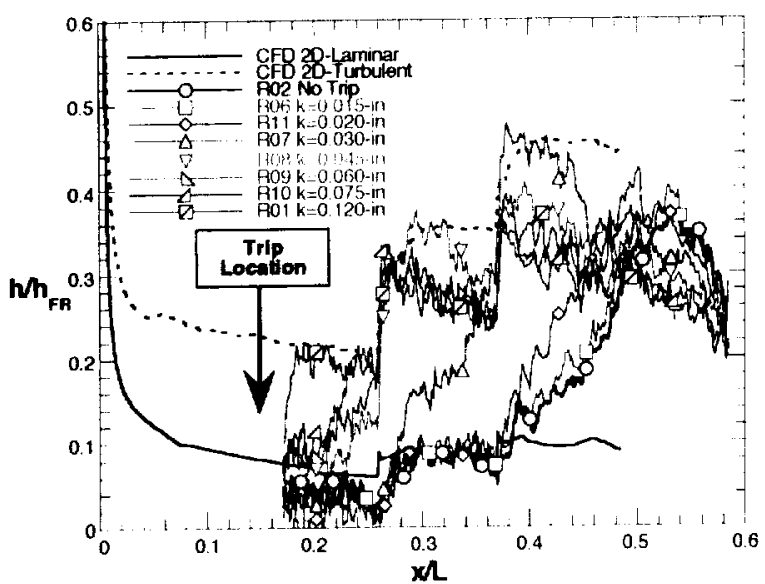

Figure 10. Effect of trip height for Trip 1 on centerline heating profiles at Mach 6, $\alpha=2-\mathrm{deg}$, and $\operatorname{Re}=2.2 \times 10^{6} / \mathrm{ft}$.

Trip $1, k=0.015$-in

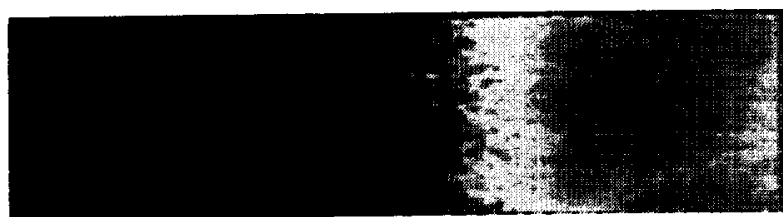

Trip $1, k=0.0 .30$-in

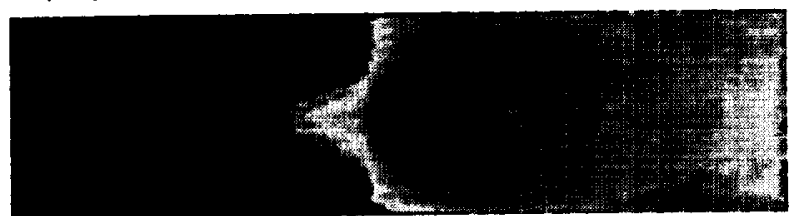

Trip $1, k=0.060$-in

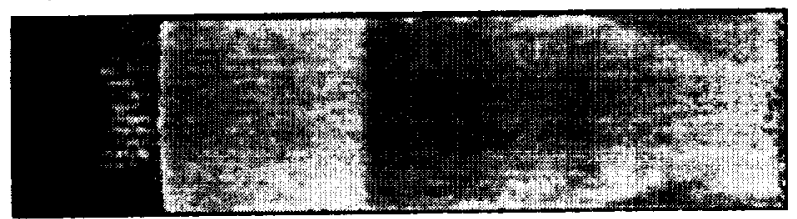

Trip $1, k=0.120$-in

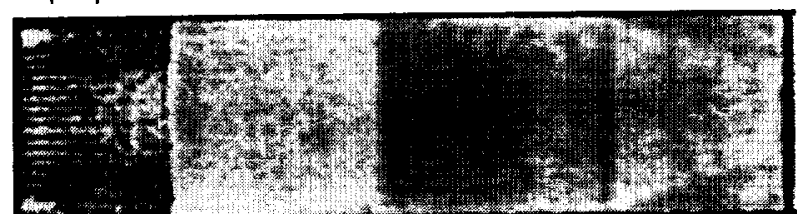

Figure 11. Trip 1 phosphor heating images for various trip heights at Mach 6, $\alpha=2$-deg, and $\operatorname{Re}=$ $2.2 \times 10^{6} / \mathrm{ft}$.

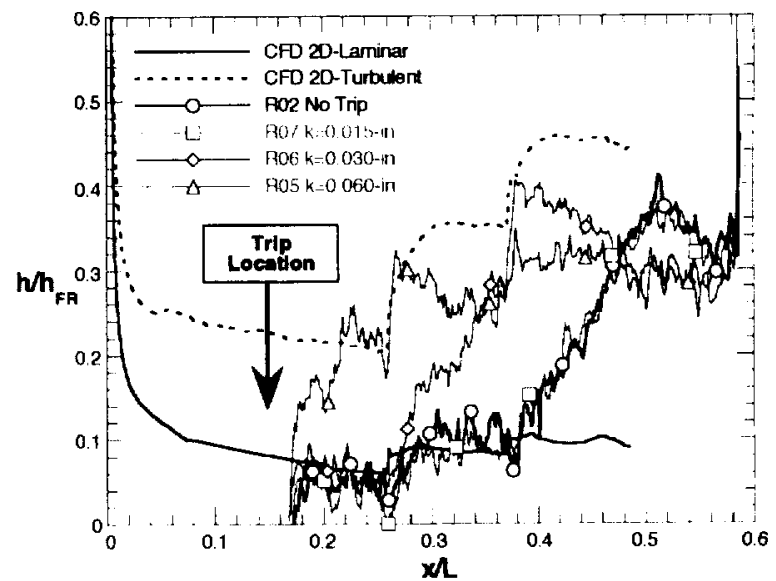

Figure 12. Effect of trip height for Trip 2c on centerline heating profiles at Mach 6, $\alpha=2$-deg, and $\operatorname{Re}=2.2 \times 10^{6} / \mathrm{ft}$.

Trip $x, k=0.015$-in

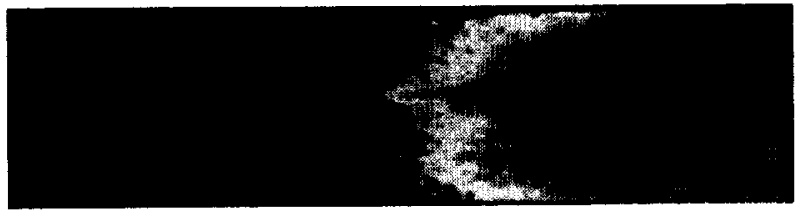

Trip $x, k=0.030$-in

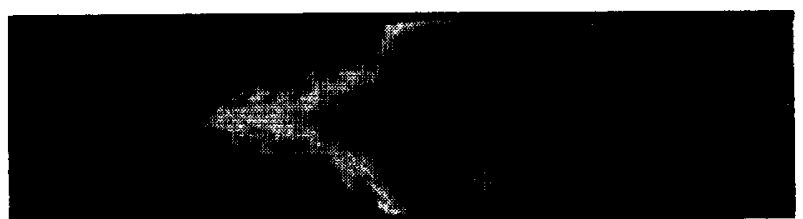

Trip $2 x, k=0.060$-in

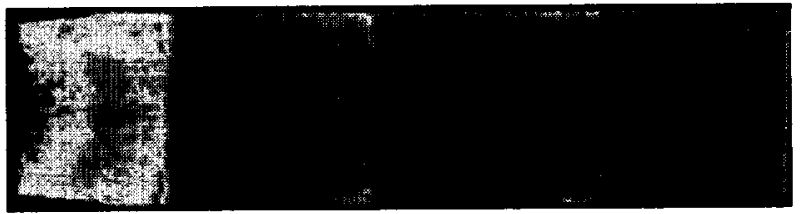

Figure 13. Trip $2 \mathrm{c}$ phosphor heating images for various trip heights at Mach 6, $\alpha=2-\mathrm{deg}$, and $\mathrm{Re}=$ $2.2 \times 10^{6} / \mathrm{ft}$.

Trip 1 vortices

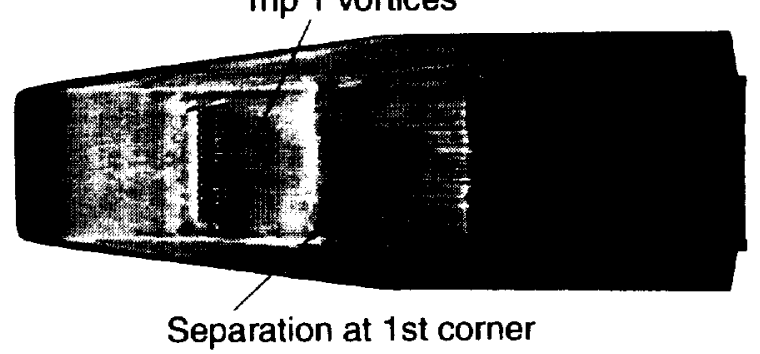

Figure 14a. Oil-flow on Hyper- $X$ forebody model at Mach 6 with Trip 1, k=0 030-in, $\alpha=2$-deg, and Re = $2.2 \times 10^{6} / \mathrm{ft}$. 



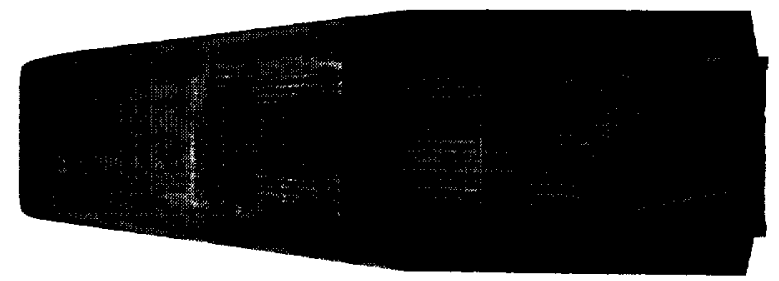

Figure 14b. Oil-flow on Hyper-X forebody model at Mach 6 with Trip 1, $\mathrm{k}=0060$-in, $\alpha=2$-deg, and $\mathrm{Re}=$ $2.2 \times 10^{6} / \mathrm{ft}$.

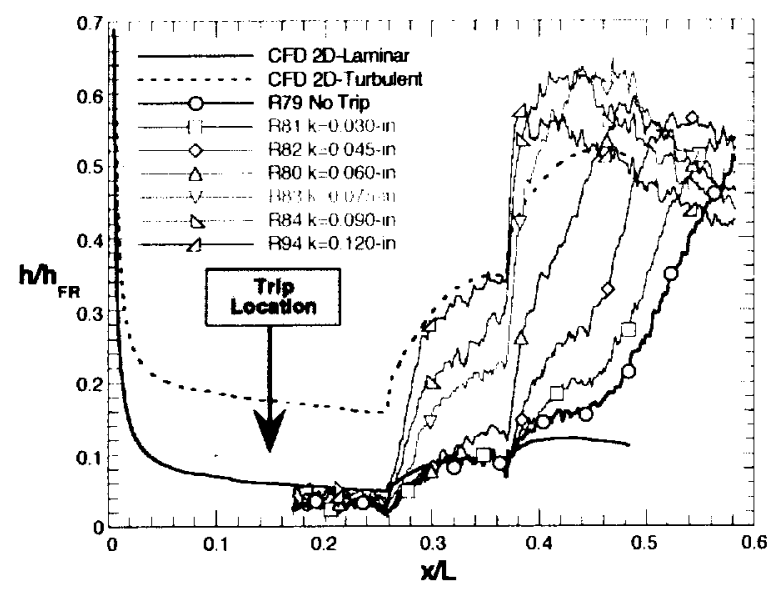

Figure 15. Effect of trip height for Trip 1 on centerline heating profiles at Mach 10, $\alpha=2$-deg, and $\operatorname{Re}=2.2 \times 10^{6} / \mathrm{ft}$.

Trip $1, k=0.030$-in

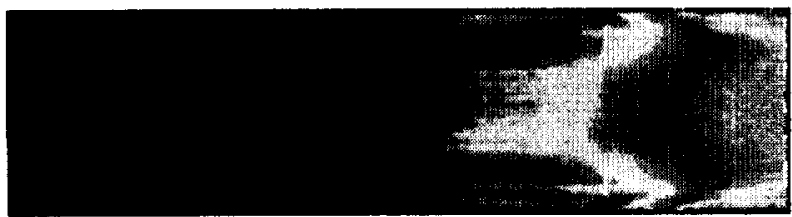

Trip $1, k=0.060$-in

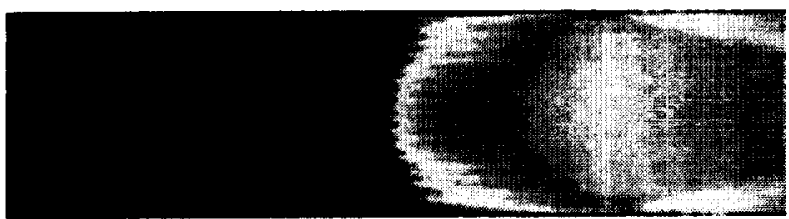

Trip $1, k=0.120$-in

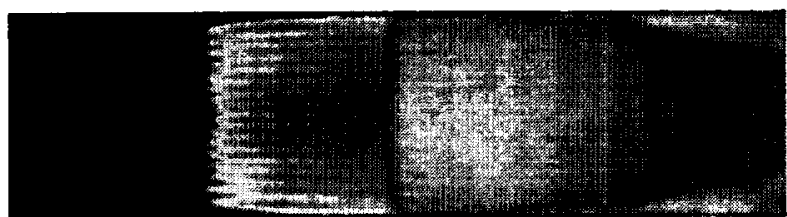

Figure 16. Trip 1 phosphor heating images for various trip heights at Mach 10, $\alpha=2-\mathrm{deg}$, and $\mathrm{Re}=$ $2.2 \times 10^{6} / \mathrm{ft}$

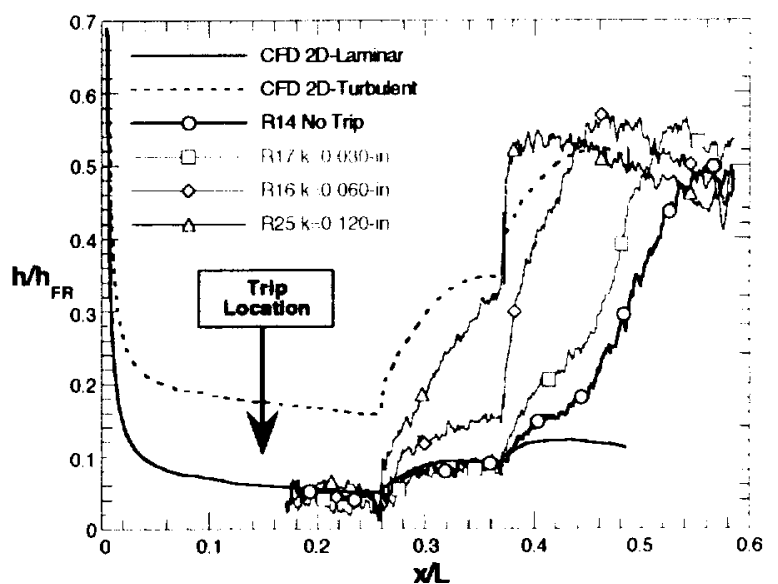

Figure 17. Effect of trip height for Trip $2 \mathrm{c}$ on centerline heating profiles at Mach 10, $\alpha=2-\mathrm{deg}$, and $\operatorname{Re}=2.2 \times 10^{6} / \mathrm{ft}$.

Trip $x, k=0.030$-in

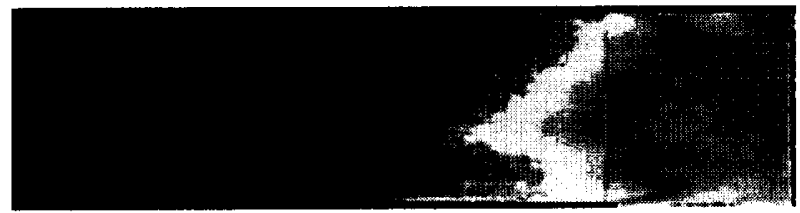

Trip $x, k=0.060$-in

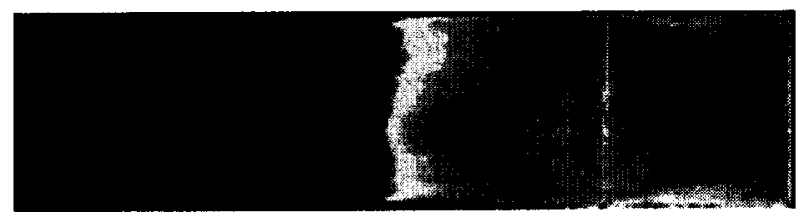

Trip $x, k=0.120$-in

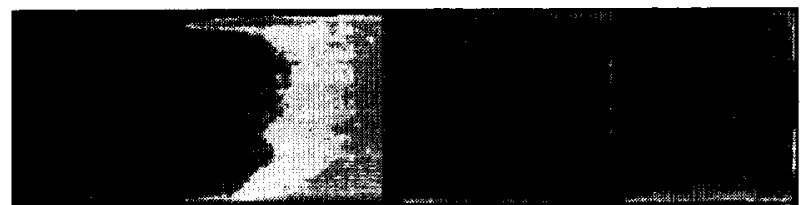

Figure 18. Trip $2 \mathrm{c}$ phosphor heating images for various trip heights at Mach 10, $\alpha=2-\mathrm{deg}$, and $\operatorname{Re}=$ $2.2 \times 10^{6} / \mathrm{ft}$.

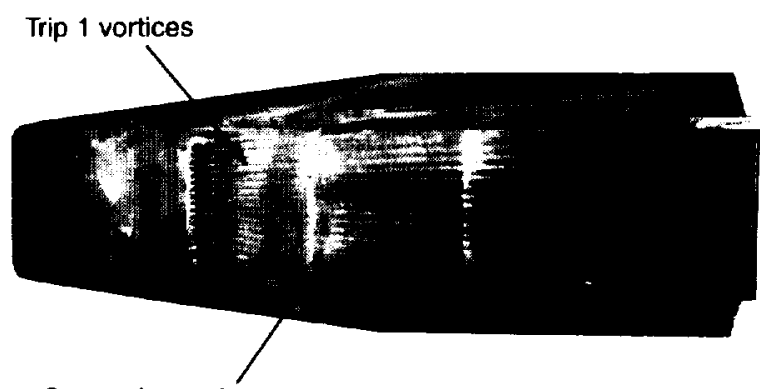

Separation at 1 st corner

Figure 19a. Oil-flow on Hyper- $X$ forebody model at Mach 10 with Trip 1, k=0.060-in, $\alpha=2$-deg, and $\operatorname{Re}=2.2 \times 10^{6} / \mathrm{ft}$. 



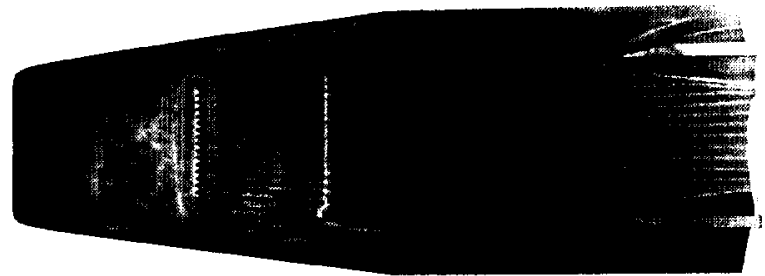

Figure 19b. Oil-flow on Hyper-X forebody model at Mach 10 with Trip $1, k=0.120$-in, $\alpha=2$-deg, and $\operatorname{Re}=2.2 \times 10^{6} / \mathrm{ft}$.

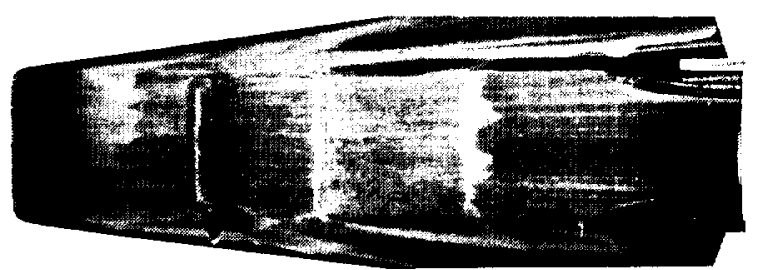

Figure 19c. Oil-flow on Hyper-X forebody model at Mach 10 with Trip 2b, $k=0.060$-in, $\alpha=2$-deg, and $\operatorname{Re}=2.2 \times 10^{6} / \mathrm{ft}$

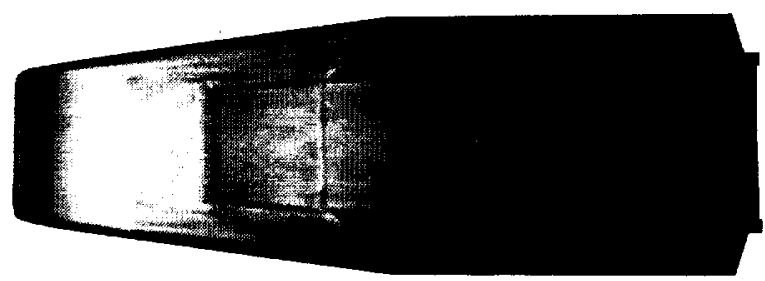

Figure 19d. Oil-flow on Hyper- $X$ forebody model at Mach 10 with Trip 2b, $k=0.120$-in, $\alpha=2$-deg, and $\operatorname{Re}=2.2 \times 10^{6} / \mathrm{ft}$.

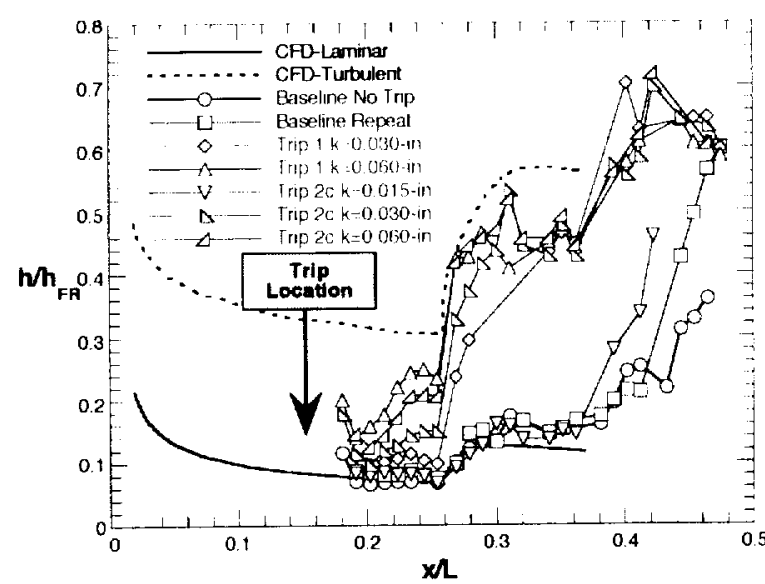

Figure 20. Effect of trip height for Trip 1 and $2 c$ on centerline heating profiles at Mach 7 in HYPULSE, $\alpha$ $=2-\mathrm{deg}$, and $\operatorname{Re}=1.4 \times 10^{6} / \mathrm{ft}$.

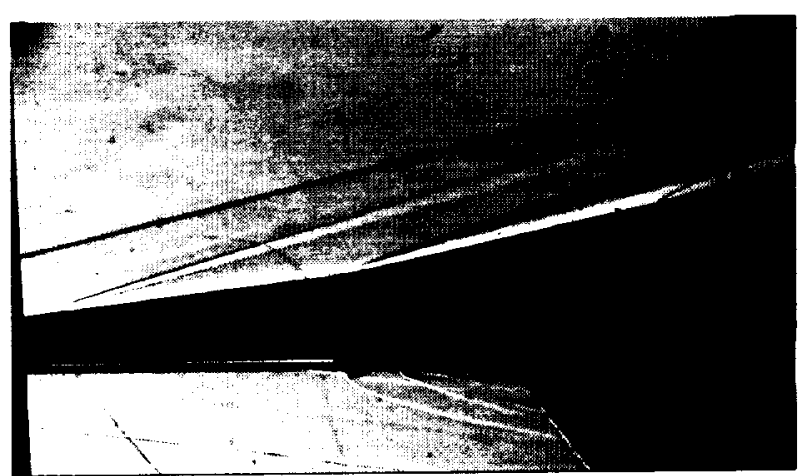

Figure 21. Schlieren image at Mach 7 in HYPULSE with Trip 2c at $k=0.030$-in, $\alpha=2$-deg, and $\operatorname{Re}=1.4 \times 10^{6} / \mathrm{ft}$.

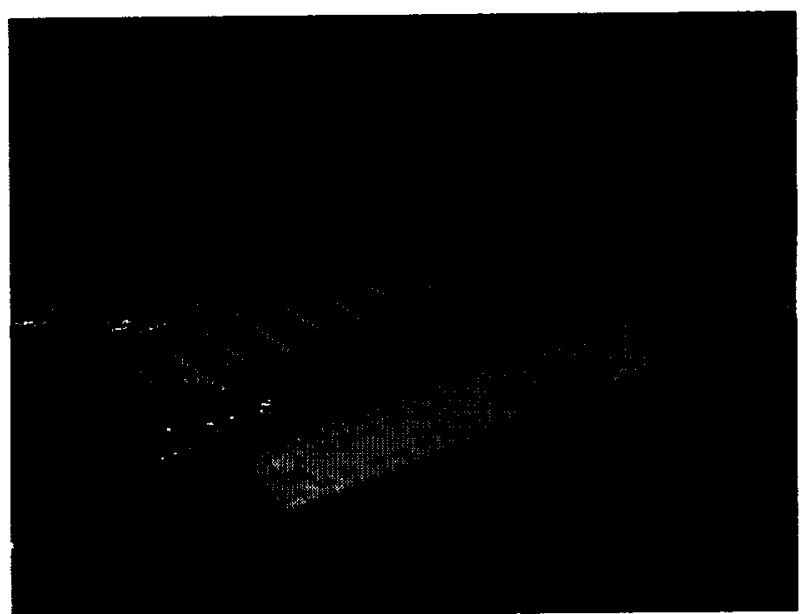

Figure 22. Close-up photograph of proposed trip scaled for flight conditions.

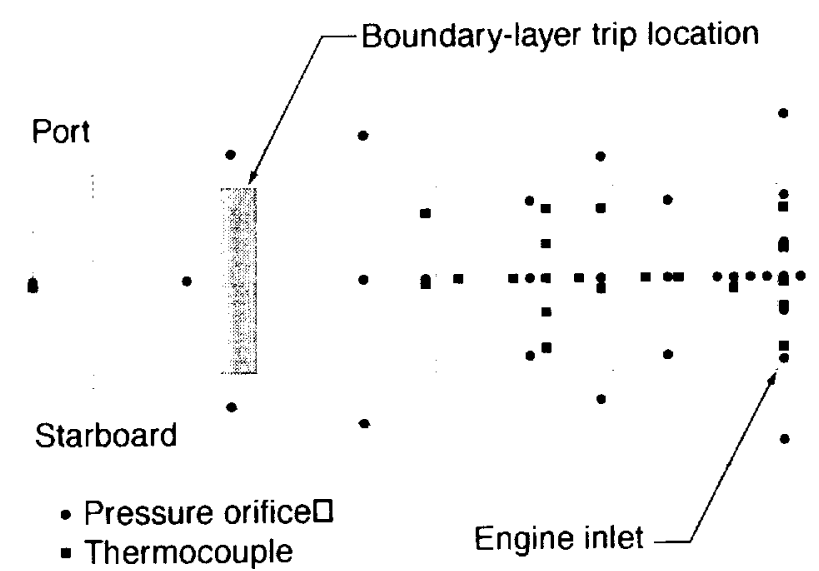

Figure 23. Sketch of flight instrumentation for the Mach 7 vehicle forebody. 


